\title{
Cenários da Diversidade: Variedades de Capitalismo e Política Industrial nos EUA, Alemanha, Espanha, Coreia, Argentina, México e Brasil (1998-2008)*
}

Ignacio Godinho Delgado Eduardo Salomão Condé Angelo Brigato Ésther III Helena da Motta Salles ${ }^{\text {IV }}$
IProfessor associado da Universidade Federal de Juiz de Fora (UFJF) e pesquisador do Instituto Nacional de Ciência e Tecnologia - Políticas Públicas, Estratégias e Desenvolvimento (INCT-PPED). E-mail: ignacio.delgado@ufjf.edu.br. IIProfessor adjunto do Departamento de Ciências

Sociais, da Universidade Federal de Juiz de Fora (UFJF) e pesquisador associado ao Instituto Nacional de Ciência e Tecnologia - Políticas Públicas, Estratégias e Desenvolvimento (INCT-PPED). E-mail: eduardosconde@uol.com.br.

III Professor adjunto, pesquisador do Departamento de Ciências Administrativas, da Faculdade de Administração e Ciências Contábeis (FACC), da Universidade Federal de Juiz de Fora (UFJF), e do Instituto Nacional de Ciência e Tecnologia - Políticas Públicas, Estratégias e Desenvolvimento (INCT-PPED). E-mail: angelo.esther@ufjf.edu.br.

${ }^{\text {IV }}$ Professora (aposentada) do Departamento de Ciências Sociais, da Universidade Federal de Juiz de Fora (UFJF) e pesquisadora do Instituto Nacional de Ciência e Tecnologia - Políticas Públicas, Estratégias e Desenvolvimento (INCT-PPED).

\section{APRESENTAÇÃO}

$\mathrm{O}$ artigo que se segue dispõe de três seções. Na primeira, discorremos sobre as formulações de Hall e Soskice (2001) em relação às variedades de capitalismo, com as retificações propostas na pesquisa Estudo comparativo de política industrial: as trajetórias do Brasil, Argentina, México, Coreia do Sul, EUA, Espanha e Alemanha․ A partir daí, é apresentado um quadro comparativo dos países indicados acima, considerando os diferentes domínios institucionais presentes nas variedades de capitalismo. Na segunda seção são apresentadas as principais definições de política industrial dos países em tela, desde 1998 até 2008. Por fim, nas considerações finais, busca-se avaliar as medidas de política industrial pertinentes ao ambiente institucional brasileiro, bem como as potencialidades de mudança sugeridas pela análise realizada.

\footnotetext{
* Os autores são professores da Universidade Federal de Juiz de Fora (UFJF) e integram o Instituto Nacional de Ciência e Tecnologia - Políticas Públicas e Estratégias de Desenvolvimento (INCT-PPED). Este artigo ancora-se, ainda, em pesquisas desenvolvidas com apoio da Fundação de Amparo à Pesquisa do Estado de Minas Gerais (FAPEMIG) e da Agência Brasileira de Desenvolvimento Industrial (ABDI). Destaque para o projeto Estudo Comparativo de política industrial: as trajetórias do Brasil, Argentina, México, Coréia do Sul, EUA, Espanha e Alemanha, contratado pela ABDI, que contou com participação dos estudantes Breno Vieira de Freitas, Bruna Paiva Lenzi, Carlos Eduardo Ferreira Fernandes, Diogo de Carvalho Antunes Silva, Diogo Gomes de Campos, Fernando Marcus Nascimento Vianini, Heitor de Andrade Carvalho Loureiro, Maedison de Souza, Priscila Musquim Alcântara, Rene Eberle Rocha, William Rezende Alves Ponte.
}

DADOS - Revista de Ciências Sociais, Rio de Janeiro, vol. 53, n-4 4, 2010, pp. 959 a 1008. 
No limite, sugere-se que o sucesso da indústria dos diferentes países em atividades de inovação tecnológica está associado à redução da incerteza proporcionada às firmas, no âmbito de determinados ambientes institucionais, para os investimentos em inovação. Importa assinalar, contudo, que isto não implica a presença de um conjunto de instrumentos universais, tomados como as melhores práticas, assimiláveis por qualquer país. De fato, a redução da incerteza é proporcionada por mecanismos de indução às atividades inovativas adequados a diferentes configurações institucionais, neste artigo consideradas a partir de indicações sugeridas pela abordagem sobre as variedades de capitalismo. No caso brasileiro, salienta-se que o predomínio de traços liberais nos domínios interativos que emolduram a relação entre as firmas e o mundo do trabalho (relações industriais, atividades de qualificação, relações entre as direções e os empregados) favorece a utilização das compras governamentais como mecanismo por excelência para a redução da incerteza. Todavia, o peso do legado corporativo - conquanto incapaz de dotar as organizações de empresários e trabalhadores de condições para assegurar sua lealdade a pactos mais abrangentes - permite vislumbrar reformas que acentuem a propensão a processos de redução da incerteza que envolvam maior colaboração entre os atores presentes no mundo da produção, bem como destes com o Estado, para atividades de inovação.

\section{DOMÍNIOS INSTITUCIONAIS DAS VARIEDADES DE CAPITALISMO}

Os anos que se seguiram às crises da Coreia e do Brasil, em 1998, foram marcados pela perda de fôlego da crença, predominante desde o início da década de 1990, segundo a qual os sinais e mecanismos de mercado são condição suficiente para o desenvolvimento. Emerge, com isto, uma vasta literatura que busca salientar a diversidade de trajetórias seguida pelos países capitalistas, em contraste com a perspectiva que apontava, no rastro dos processos de globalização, uma tendência crescente à convergência. Neste sentido, dimensões como financiamento, relações industriais, sistemas de qualificação, mecanismos de governança e coordenação entre as firmas, Estado, padrões de competição, sistemas de bem-estar, de forma dedutiva ou indutiva, passaram pelo escrutínio de diversas análises que, em boa medida, preocuparam-se em identificar tipos diferentes de capitalismo (Hall e Soskice, 2001; Hollingsworth e Boyer, 1997; Whitley, 1999; Amable, 2003; Schneider, 2008) ${ }^{2}$. Não é o que se pretende aqui. Apesar da importância das tipologias associadas a tais abordagens, nosso objetivo é identifi- 
car os ambientes institucionais que envolvem a operação das empresas nos países focalizados, tomando as formulações de Hall e Soskice como recurso heurístico, de modo a perceber determinados padrões de política industrial e as potenciais respostas das empresas a ela. No limite, o que se pretende é, comparando diferentes configurações nacionais, identificar o que é pertinente ao ambiente institucional brasileiro, bem como as possibilidades de mudança que este encerra, no sentido de tornar mais efetivas as medidas de política industrial.

De todas as formulações associadas à ideia de variedades de capitalismo, a obra de Hall e Soskice dispõe de relevo especial para os estudos de política industrial por colocar no centro de sua análise as firmas e o modo como enfrentam seus dilemas de coordenação. Políticas industriais buscam, fundamentalmente, criar estímulos ao investimento privado, para objetivos diversos (emparelhamento, inovação, promoção do emprego), por meio da alteração dos preços relativos e da redução da incerteza quanto ao retorno de tais investimentos. Definida a política, espera-se que seja acompanhada de um conjunto articulado, ainda que descentralizado, de decisões de investimento capazes de provocar efeitos que atendam aos seus objetivos (Delgado, 2005, 2009; Suzigan e Furtado, 2005; Castro, 2002; Chang, 1994). As firmas, contudo, tomam suas decisões em ambientes institucionais diferenciados. As formulações de Hall e Soskice fornecem pistas para a identificação dos elementos centrais de tais ambientes. Em sua versão original, são apontados cinco domínios interativos relevantes para a estratégia empresarial, que tendem a se reforçar mutuamente (Hall e Soskice, 2001). A governança corporativa, ao lado dos vínculos entre as empresas e as finanças, é a primeira destas dimensões. Três domínios referem-se a diferentes esferas do mundo do trabalho, a saber, questões ligadas à qualificação da mão de obra, às relações industriais e à relação das firmas com seus empregados. Por fim, dilemas de coordenação aparecem também nas relações interfirmas, associadas aos elos entre fornecedores e clientes ${ }^{3}$.

Hall e Soskice destacaram dois padrões polares de interação estratégica das empresas, num espectro em que formas mistas também podem aparecer. Tais tipos são as economias de mercado liberais, em que prevalecem processos de coordenação guiados pelos mecanismos de mercado (os EUA são o paradigma), e as economias de mercado coordenado, em que prevalece a concertação entre os diferentes atores envolvidos (a Alemanha é o paradigma). Em cada um destes casos, desenvolvem-se van- 
Ignacio G. Delgado, Eduardo S. Condé, Angelo B. Ésther e Helena da M. Salles

tagens institucionais comparativas que estimulam o apego das empresas às formas de interação predominantes.

No que se refere às atividades de inovação, a abordagem sobre as variedades de capitalismo sugere que as formas liberais favorecem a ocorrência mais acentuada de inovações radicais, ao passo que as formas coordenadas favorecem a ocorrência de inovações incrementais ${ }^{4}$. As primeiras seriam mais afeitas aos fast-moving technology sectors, que envolvem design ligeiro e desenvolvimento rápido de produtos e processos, como a biotecnologia, semicondutores, software, vinculando-se, ainda, à provisão de componentes para outros setores, como telecomunicações, dispositivos operacionais do sistema financeiro, defesa e lazer (cf. ibid.). A estratégia competitiva das firmas estaria relacionada à capacidade de correr riscos com novos produtos, bem como à implementação rápida. Além dos padrões de financiamento e de governança corporativa, tal estratégia é favorecida pelas relações entre as firmas e o mundo do trabalho, marcadas pelo predomínio do mercado e não da concertação que, embora não conduzam à cooperação para ações inovativas, estimulam a disposição de largar na frente na disputa de mercados, com produtos novos devidamente protegidos pelo segredo industrial, desenvolvidos por laboratórios em geral dissociados e protegidos do ambiente do chão da fábrica e da relação com outros atores, ou, ainda, por novas gerações de empresários. Novidade e preço são os elementos fundamentais da estratégia competitiva.

As inovações incrementais, por seu turno, estariam mais associadas à produção de bens de capital, como máquinas e equipamentos industriais, bens de consumo duráveis, artefatos e equipamentos de transporte (id.). Neste caso, o que se busca é a introdução de inovações que aperfeiçoem a qualidade de uma linha de produção já estabelecida, de modo a garantir a lealdade do consumidor, além de assegurar a redução progressiva dos custos. A sugestão é que as formas de financiamento e os padrões de governança corporativa das formas coordenadas seriam mais afeitas a este esforço, uma vez que permeáveis às estratégias de longo prazo e à cooperação entre as firmas e outros atores relevantes, como institutos de pesquisa e universidades. Ademais, a relação das firmas com o mundo do trabalho, baseadas na cooperação contínua e na confiança recíproca, predispõem à busca permanente de aperfeiçoamento na produção, embora não favoreçam o segredo industrial. Há pouco espaço para o aparecimento continuado de novas gerações em- 
presariais. Qualidade e lealdade do consumidor são os elementos-chave da estratégia competitiva ${ }^{5}$.

A abordagem sobre as variedades de capitalismo assinala que as políticas públicas tendem a ser igualmente afetadas pelas características do ambiente institucional (id.) ${ }^{6}$. Assim, nas formas liberais o predomínio do mercado nos processos de coordenação tornaria as empresas mais sensíveis a incentivos propriamente financeiros, ao passo que, nas formas coordenadas a presença de associações vigorosas, capazes de assegurar a lealdade de seus membros para ações concertadas, favorece o desenvolvimento de disposições cooperativas por parte das empresas sem que o impacto sobre os custos seja tomado como a variável mais importante. No limite, diversos instrumentos de política industrial e tecnológica são usados indiferentemente por todos os países, porém nas formas liberais os incentivos fiscais e subsídios tendem a dispor de maior relevância, além de políticas como as compras governamentais, que permitem a redução da incerteza nos investimentos privados, por intermédio de mecanismos de mercado. Nas formas coordenadas é mais provável que prosperem programas de cooperação entre as empresas, e destas com o Estado, para o alcance de determinadas metas, não obstante a ocorrência de incentivos financeiros imediatos.

Temos lidado, como dito no início deste artigo, com a abordagem sobre as variedades de capitalismo como um instrumento heurístico para identificar, a partir as dimensões interativas apontadas acima, diferentes configurações nacionais, tomadas não como estruturas holísticas, estáticas, mas, tão-somente, como ambientes derivados de escolhas efetuadas em condições determinadas, que geram incentivos para o apego dos atores sociais à sua permanência, porém abertos à mudança, notadamente em situações de crise, a partir da orquestração de coalizões, que podem estabelecer novas configurações ${ }^{7}$ (Delgado, 2009; Delgado et alii, 2009a; Gourevitch, 1986). Ademais, adicionamos à formulação original o Estado e a inserção das economias nacionais no mercado mundial como domínios interativos de relevo para a operação das firmas (Delgado et alii, 2009a; 2009b). De fato, o Estado é uma instituição decisiva ao enforcement dos elementos que compõem o ambiente em que tal operação se realiza, qualquer que seja a variedade de capitalismo, assim como as políticas desenvolvidas por seus titulares e agências afetam de forma crucial as decisões empresariais (Polanyi, 1980; Offe e Ronge, 1984; Hancké, Rhodes e Thatcher, 2007; Schmidt, 2006). Além disto, o gasto público, mesmo nas formas liberais, é fundamental nas configu- 
rações da demanda e da estrutura do mercado ${ }^{8}$. Por seu turno, as firmas operam em ambientes econômicos nacionais mais ou menos abertos, mais ou menos protegidos, além de localizados em posições centrais, periféricas ou semiperiféricas da economia mundial, conforme a presença de atividades econômicas que encerram maior potencial inovativo, o que torna decisivo para as estratégias empresariais a inserção internacional das economias nas quais estão sediadas as firmas ${ }^{9}$ (Arrighi, 1997).

Nas Tabelas 1 e 2 apontamos alguns elementos considerados para a caracterização da indústria e das modalidades de inserção internacional das economias dos países focalizados. Merece destaque a importância do mercado interno na economia norte-americana, tão fechada quanto a brasileira. Todavia, sua enorme magnitude permite que o setor externo do país, mesmo que reduzido em relação ao Produto Interno Bruto (PIB), disponha de uma participação expressiva no comércio internacional. Do mesmo modo, embora as atividades de maior teor tecnológico apresentem, nos EUA, uma participação inferior às reveladas por Alemanha e Coreia do Sul, a dimensão superlativa da economia norte-americana mantém o país com destaque no domínio das atividades intensas em tecnologia, o que se atesta pelo peso de que dispõem os indicadores de inovação tecnológica (peso dos gastos com inovação em relação ao PIB e participação das empresas nestes gastos), inferiores, apenas, aos da Coreia do Sul e Alemanha. Esta última, pela dimensão do PIB, pela presença dos setores de maior intensidade tecnológica e pela capacidade de inovação, compõe, junto aos EUA, o grupo das economias centrais dentre os países focalizados. A Espanha aproxima-se de tal condição, pela dimensão de seu PIB e pela importância das manufaturas nas exportações. Aparece, contudo, em posição intermediária no que se refere à presença de setores de maior intensidade tecnológica. Seu desempenho nas atividades de inovação é pouco maior que o brasileiro e muito distante do evidenciado pelos EUA, Alemanha e Coreia do Sul. Esta, com uma economia aberta e protegida, dispõe de um PIB que evidencia seu deslocamento das posições ocupadas por Brasil, México e Argentina, apresentando indicadores relativos à presença de setores de maior intensidade tecnológica, participação das manufaturas na produção industrial e capacidade de inovação que sinalizam para uma trajetória acelerada rumo às posições centrais ${ }^{10}$. México e Brasil ocupam posições intermediárias, embora o Brasil revele desempenho na capacidade de inovação ligeiramente superior ao do Méxi$\mathrm{Co}^{11}$. Por fim, a Argentina apresenta indicadores, relativos à presença 
Cenários da Diversidade: Variedades de Capitalismo e Política Industrial...

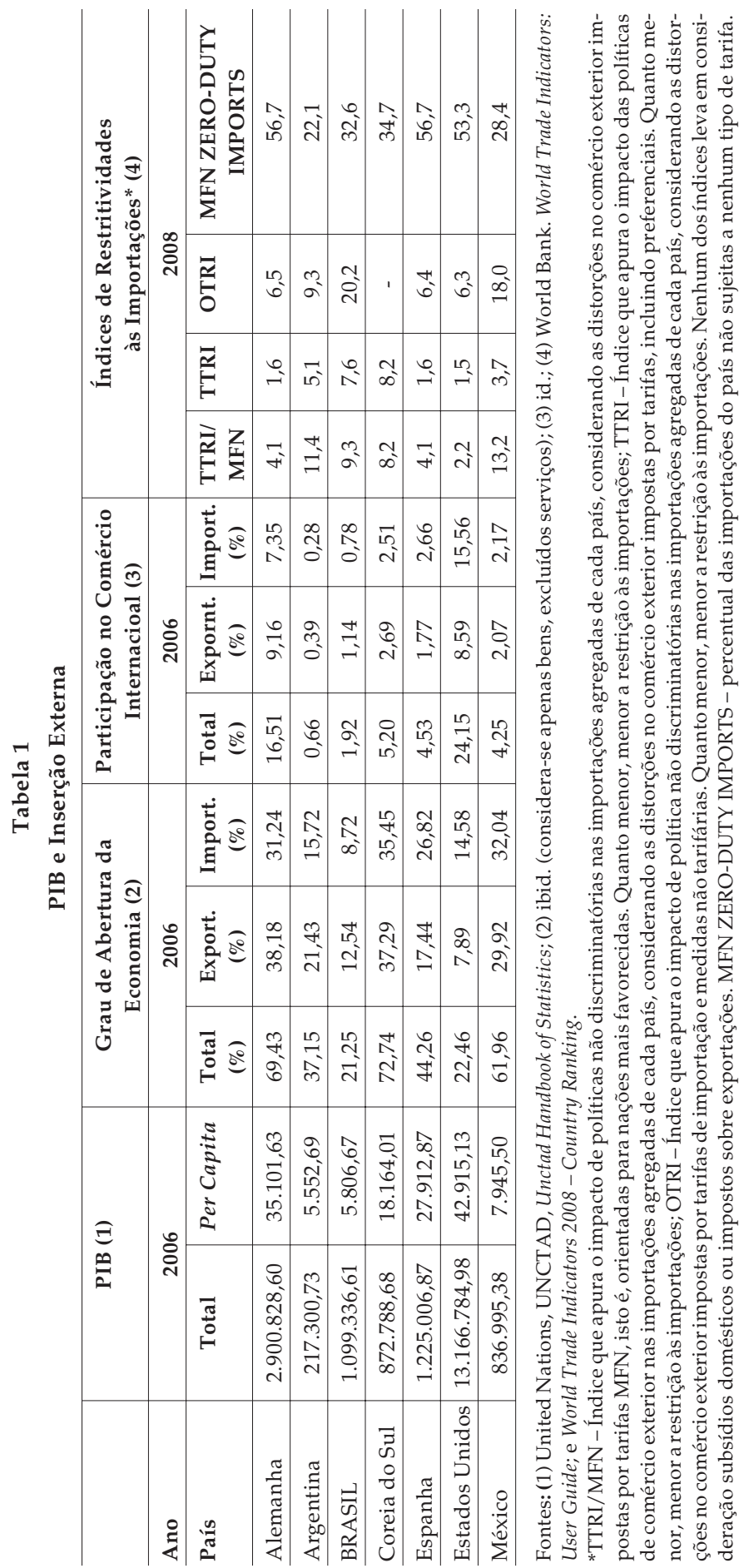


Ignacio G. Delgado, Eduardo S. Condé, Angelo B. Ésther e Helena da M. Salles

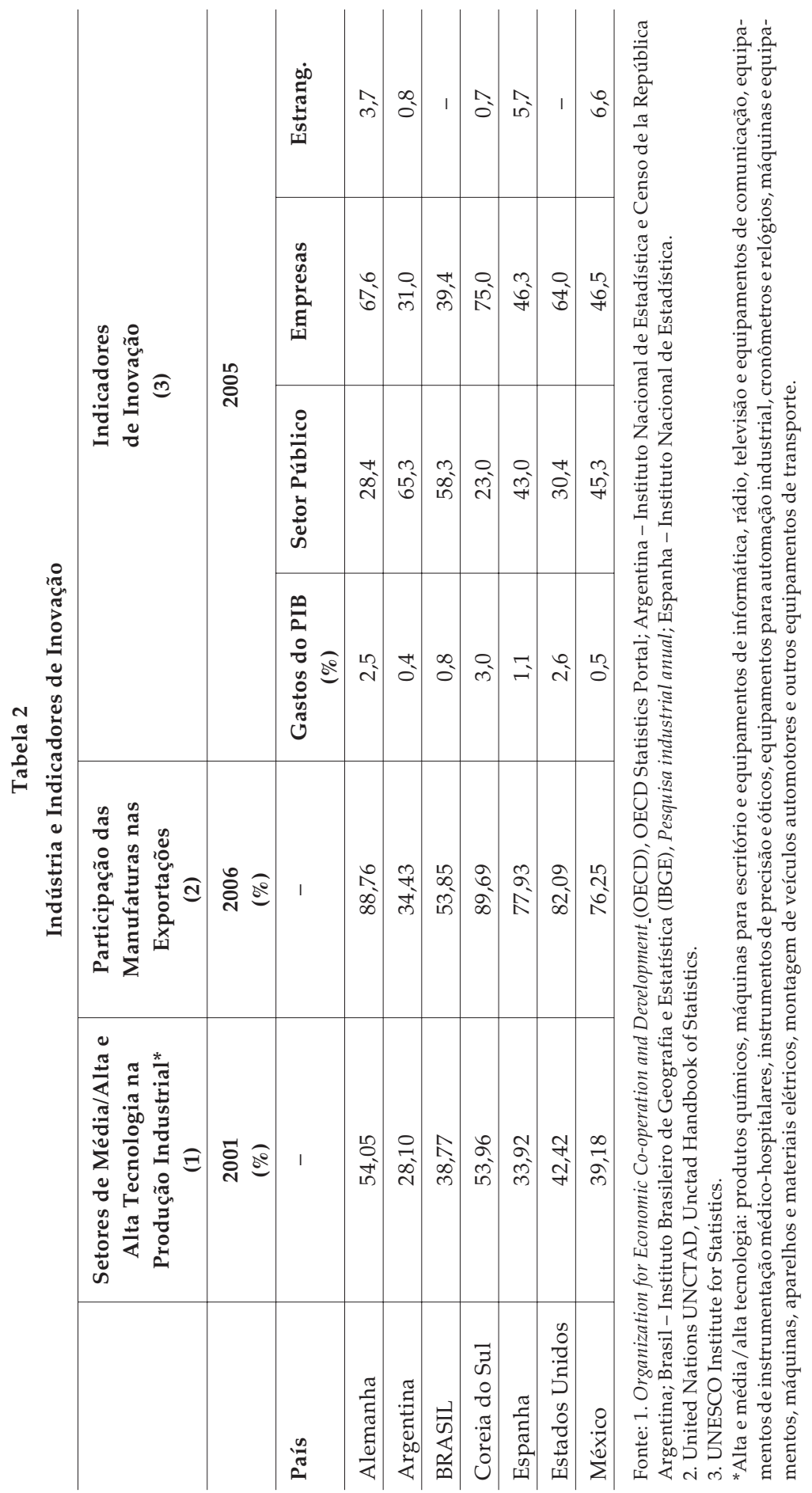


de setores de maior intensidade tecnológica e de manufaturas nas exportações, que apontam para um processo de crescente periferização.

Consideremos, pois, como os diferentes domínios institucionais apontados acima se apresentam nos países em análise.

Nos EUA predomina o mercado de capitais no financiamento das empresas, ao lado de padrões de governança corporativa marcados pelo controle das gerências sobre a gestão, no âmbito de um padrão pulverizado de propriedade acionária (Abelshauser, 2005; Gourevitch e Shinn, 2005; Aldrighi, 2003; Novaes, 2004; Rabelo e Silveira, 1999; Guimarães, 2007). Nas relações industriais prevalecem os contratos precários e atomizados, e sindicatos, em geral, frágeis. É reduzida a participação das empresas nos esforços de qualificação, que ficam sob responsabilidade dos indivíduos no mercado, ou do Estado, na educação genérica formal. É também reduzida a colaboração entre empresas e seus empregados para esforços de qualificação ou inovação. Esforços de cooperação entre as firmas têm alcance pequeno, prevalecendo mecanismos de coordenação por meio do mercado (Ramos, 2008; Rocha, 2007; Itiro, 2003; Dufovsky e Dulles, 2004; Clark et alii, 2002). As relações entre empresários e Estado não dispõem, da mesma forma, de caráter concertado, realizando-se, num cenário pluralista, por meio da prática de lobbies, pelos quais as empresas buscam posições de força na definição de medidas regulatórias e na negociação de contratos com o Estado, cujos gastos têm papel decisivo na dinamização da economia e mesmo no desempenho das firmas no que se refere à inovação tecnológica (Dahl, 1968; Jenkins-Smith e Sabatier, 1993; Lehmbruch e Schmitter, 1982; Schmitter e Streeck, 1999; Santos, 2008). Os EUA são a economia hegemônica na ordem mundial, com presença expressiva no comércio global, embora o mercado interno seja o seu mais importante fator de dinamismo (Delgado et alii, 2009a).

Na Alemanha, apesar de alterações importantes ocorridas nos últimos anos, os bancos são ainda decisivos no financiamento da produção industrial, com participação elevada na propriedade das empresas, que exibem uma estrutura de propriedade concentrada e padrões de governança marcados pela articulação entre diferentes agentes envolvidos no processo produtivo (Abelshauser, 2005; Guimarães, 2006; 2007; Novaes, 2004; Gourevitch e Shinn, 2005; Srour, 2005; Gerolomano et alii, 2008). As relações industriais na Alemanha reforçam este padrão, com contratos de longa duração, negociados com sindicatos fortes e associ- 
ações empresariais que desempenham papéis abrangentes, seja na barganha coletiva, seja em esforços de qualificação e inovação tecnológica. A prática da concertação estende-se à relação das empresas com seus funcionários, que participam de forma expressiva da gestão das firmas e de iniciativas para qualificação e inovação (Ebbinghaus e Visser, 2000; Kuckulentz, 2007). Os elos entre os empresários e o Estado, por seu turno, num cenário neocorporativo, são mediados pelas associações, em múltiplos canais de intermediação (Lehmbruch e Schmitter, 1982; Schmitter e Streeck, 1999; Guimarães, 2006; 2007a). A Alemanha exibe uma economia aberta, com poucas restrições à importação, tecnologicamente dinâmica, embora sejam de pequena expressão os segmentos industriais ligados ao paradigma microeletrônico (Delgado et alii, 2009a).

$\mathrm{Na}$ Espanha, o autofinanciamento aparece com destaque nas opções das empresas, em consonância com uma estrutura de governança em que é relevante o controle familiar das firmas, marcadas pela grande concentração da propriedade (Puga, 2002; Minguez e Martin, 2003; Leal e Camuri, 2008; Domingo et alii, 2004; Cestona et alii, 2005; Pérez de Lema, 2004). A flexibilização crescente dos contratos de trabalho nas relações industriais tem reduzido o peso dos sindicatos, inibido disposições de colaboração entre as firmas e seus empregados, além de deixar pouco espaço para ações coordenadas de qualificação e inovação, apesar do crescimento das iniciativas de cooperação entre as firmas cujo foco não tem sido, contudo, voltado para aqueles intentos -, bem como dos programas públicos de qualificação (Serrano et alii, 2007; Ebbinghaus e Visser, 2000; Rozicki, 1997). Os elos entre empresas e Estado na Espanha seguem um padrão corporativo marcado pela forte influência de vínculos familiares entre elites políticas e burocráticas e proprietários das empresas (Schmidt, 2006; Cabrera e Del Rey, 2007) A economia do país, apesar do PIB per capita elevado, tem revelado baixa presença de setores de alta tecnologia em sua estrutura industrial, abertura comercial e participação no comércio internacional medianas, com poucas restrições às importações (Delgado et alii, 2009a).

No caso da Coreia do Sul, os bancos públicos são decisivos no financiamento da indústria. A estrutura concentrada da propriedade na neste país é acompanhada do controle familiar dos grandes conglomerados, num modelo de governança corporativa hierárquico em que é reduzida a participação de acionistas e trabalhadores (Cho e Kim, 2007; Novaes, 2004; OECD, 2003a). Os contratos de longa duração, que são uma das 
marcas das relações industriais na Coreia do Sul, não resultam da concertação entre empresas e sindicatos, em geral fracos e atomizados, acarretando um padrão de cooperação entre empresas e seus funcionários assimétrico, mas com forte identificação dos trabalhadores com as empresas. Estas se envolvem em atividades de qualificação e recrutam funcionários para ações inovativas, mas deixam pouco espaço para a presença dos mesmos na gestão (Verma et alii, 1995; Choong-Young, 1998; Kim, 2005). Relações de cooperação interfirmas são comuns no âmbito dos chaebols e entre estes e firmas estrangeiras, mas o Estado impõe rígidos limites para que a cooperação resulte em transferência de tecnologia, ao lado do desenvolvimento de capacidade de inovação endógena. A relação do Estado com o empresariado realiza-se via contatos diretos com os chaebols e a federação industrial que controlam, e tem sido marcada pela forte disposição indutiva do primeiro, embora a consolidação dos chaebols tenha acentuado sua autonomia (Graham, 2003; Guimarães, 2007b; Haggard, Lim e Kim, 2003). A Coreia do Sul é uma economia fortemente integrada ao mercado mundial, mas protegida, revelando grande capacidade de inovação tecnológica (Delgado et alii, 2009a).

$\mathrm{Na}$ Argentina, os bancos cumprem papel importante no financiamento das indústrias, embora não disponham de peso expressivo na propriedade das empresas, a exemplo da Alemanha. O autofinanciamento e os recursos externos são, também, expressivos. O conglomerado familiar sempre teve papel importante na organização das empresas, cujo modelo de governança corporativa segue o padrão latino-americano, com acentuado controle familiar da gestão, embora tenha se elevado a presença de controladores estrangeiros na estrutura industrial do país (OECD, 2003a; Leal e Camuri, 2008; Schneider, 2008; Kantis et alii, 2005) As relações industriais são marcadas pelo predomínio do contrato individual e precário, em meio à sobrevivência da estrutura sindical corporativa e importante papel regulador do Estado (Diniz, 2006; Rozicki, 1997; Palomino e Trajtemberg, 2006). São pouco comuns ações de colaboração envolvendo as firmas e seus empregados, que, via de regra, estão ausentes da gestão das empresas. As relações entre Estado e empresários seguem o padrão corporativo presente em vários países latino-americanos, com tendência à acentuação de mecanismos pluralistas (Schneider, 2004). A economia argentina é medianamente aberta e pouco protegida, com reduzida presença de setores de alta tecnologia e baixa capacidade de inovação (Delgado et alii, 2009a). 
No México destaca-se o autofinanciamento das empresas, embora seja crescente a participação do capital externo. O controle familiar, na governança corporativa, acompanha um padrão de propriedade industrial bastante concentrada, no âmbito do conglomerado familiar, que predomina, ao lado das multinacionais, na estrutura industrial do país (Puga, 2002; OECD, 2003; Leal e Camuri, 2008; Novaes, 2004). Contratos individuais e precários são crescentes, junto a uma estrutura sindical que tem adquirido perfil pluralista, o que revela um processo crescente de americanização das relações industriais (Bensusán, 2003; 2007; Ramos, 2008; Rozicki, 1997; OCDE, 2006; Medina, 2003). Apesar de associações empresariais fortes, são escassas as experiências de colaboração entre as firmas (Schneider, 2004). Do mesmo modo, não obstante as disposições legais que buscam estimular as empresas nas atividades de qualificação, a importância destas e do Estado é reduzida para o alcance deste objetivo. Os trabalhadores, por seu turno, estão, de maneira geral, ausentes das esferas de gestão das empresas, que mantêm com seus empregados relações em que têm pouca incidência ações colaborativas. Padrões corporativos de articulação com o Estado subsistem nas relações entre as empresas e o poder público, embora com reforço da diversidade na representação de interesses do empresariado, num cenário de acentuação do pluralismo (Schneider, 2004; Carvalho, 1997). O México é uma economia aberta, que ostenta níveis elevados de proteção, exceto para os países que compõem o Tratado Norte-Americano de Livre Comércio (NAFTA), destino da maior parte de suas exportações, pouco diversificadas. É importante a presença de setores de alta tecnologia na indústria mexicana, embora concentrada em alguns setores, mas reduzida a capacidade inovativa de suas empresas (Delgado et alii, 2009a).

No Brasil predominam o autofinanciamento e os bancos públicos, no financiamento das empresas, não obstante a expansão do mercado de capitais. Prevalecem os conglomerados familiares entre as grandes empresas nacionais, mas é expressiva a presença de empresas estrangeiras. A propriedade é concentrada, e na governança corporativa destacam-se o controle familiar e pequena participação de acionistas e funcionários (Fontes Filho e Picolin 2008; OECD, 2003b; Leal e Camuri, 2008; Novaes, 2004; Gerolomano et alii, 2008). Nas relações industriais o contrato individual predomina, em meio à presença do Estado na regulação de direitos individuais do trabalho (Lobo, 2010; Werneck Vianna, 1976). O corporativismo sindical, que rege as organizações patronais e de trabalhadores, convive com a crescente diversificação da estrutura 
de representação de interesses (Diniz e Boschi, 1979; 1993; Leopoldi, 2000; Delgado, 1997). São escassas as ações de colaboração entre empresas e empregados para inovação e qualificação, efetuada por agências semipúblicas, que oferecem formação profissional elementar, ao lado da formação geral, garantida pelo Estado. Ao lado das relações hierárquicas, no interior dos conglomerados familiares, iniciativas para a colaboração entre as firmas têm sido estimuladas pelo Estado, como os fóruns de competitividade, envolvendo os segmentos das cadeias produtivas dos setores, além do apoio a clusters e arranjos produtivos locais, mas seu impacto ainda é pequeno. A relação Estado-empresariado no Brasil tem se efetuado por uma multiplicidade de canais, pluralistas e corporativos, sendo que os últimos, esvaziados na década passada, retomaram sua importância. Todavia, eles têm servido pouco à orquestração de ações concertadas (Mancuso, 2004; Diniz e Boschi, 1993; Delgado, 2005). Dotado de vigoroso mercado interno, a economia brasileira tem se mantido relativamente fechada, com níveis ainda elevados de proteção, sem superar as deficiências de sua capacidade de inovação tecnológica (Delgado et alii, 2009a).

O Quadro 1 a seguir, apresenta uma síntese da caracterização dos domínios institucionais das variedades de capitalismo, nos países em análise, com as retificações que sugerimos às formulações de Hall e Soskice.

\section{POLÍTICA INDUSTRIAL: OBJETIVOS E INSTRUMENTOS}

A criação de condições para o desenvolvimento de empresas dotadas de capacidade inovativa tem sido apontada como o principal objetivo das modernas políticas industriais. Neste sentido, elas distanciam-se das políticas que buscam tão-somente corrigir falhas de mercado, bem como daquelas orientadas para a equiparação de países atrasados aos padrões econômicos e tecnológicos presentes nas economias que ocupam posições centrais na economia mundial ${ }^{12}$.

Políticas industriais orientadas para a correção de falhas de mercado estão vinculadas a modalidades de intervenção estatal ex post, destinadas à instauração de situações de equilíbrio prejudicadas pela ocorrência de problemas como a produção de bens públicos, externalidades, informações imperfeitas, registradas pelo sistema de preços. O problema aqui é a impossibilidade de definir ações orientadas para a mudança, uma vez que situações de equilíbrio podem se verificar em estágios incipientes de desenvolvimento econômico e tecnológico, ao passo 
Ignacio G. Delgado, Eduardo S. Condé, Angelo B. Ésther e Helena da M. Salles

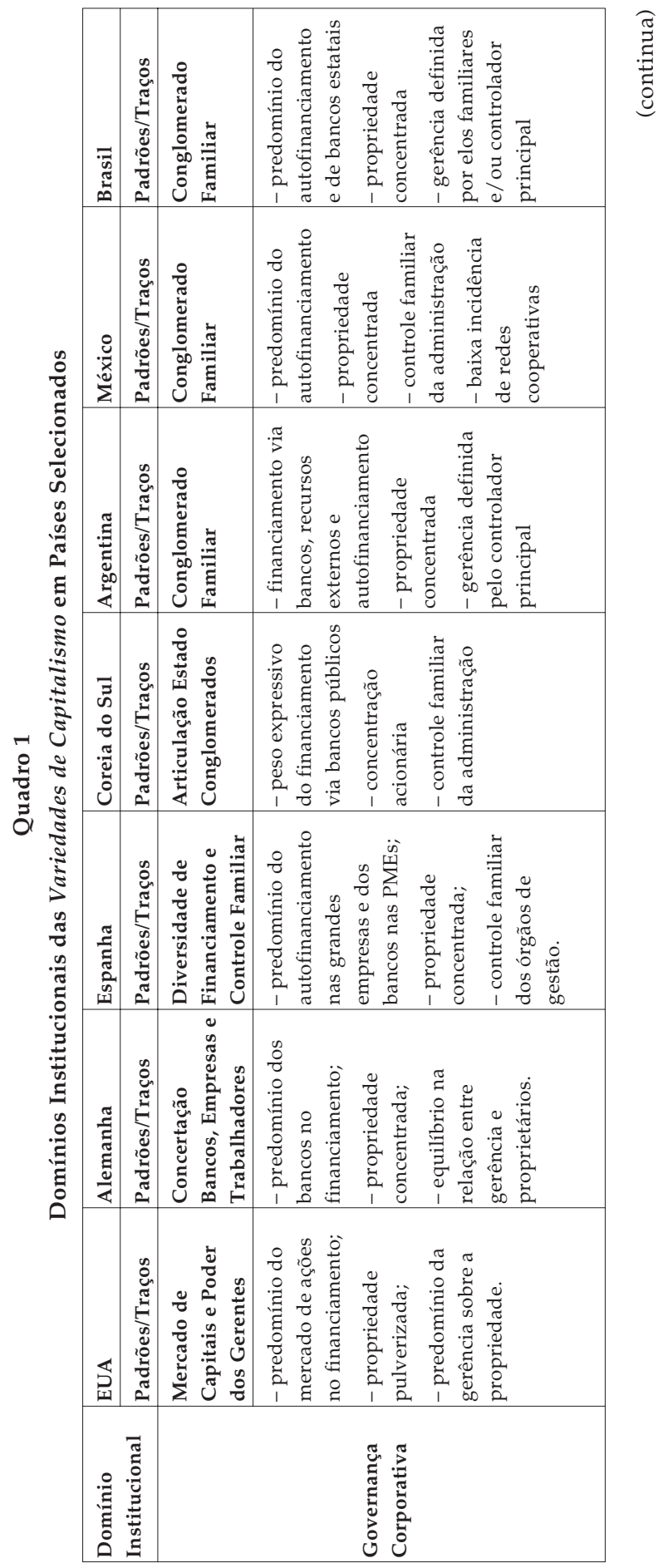


Cenários da Diversidade: Variedades de Capitalismo e Política Industrial...

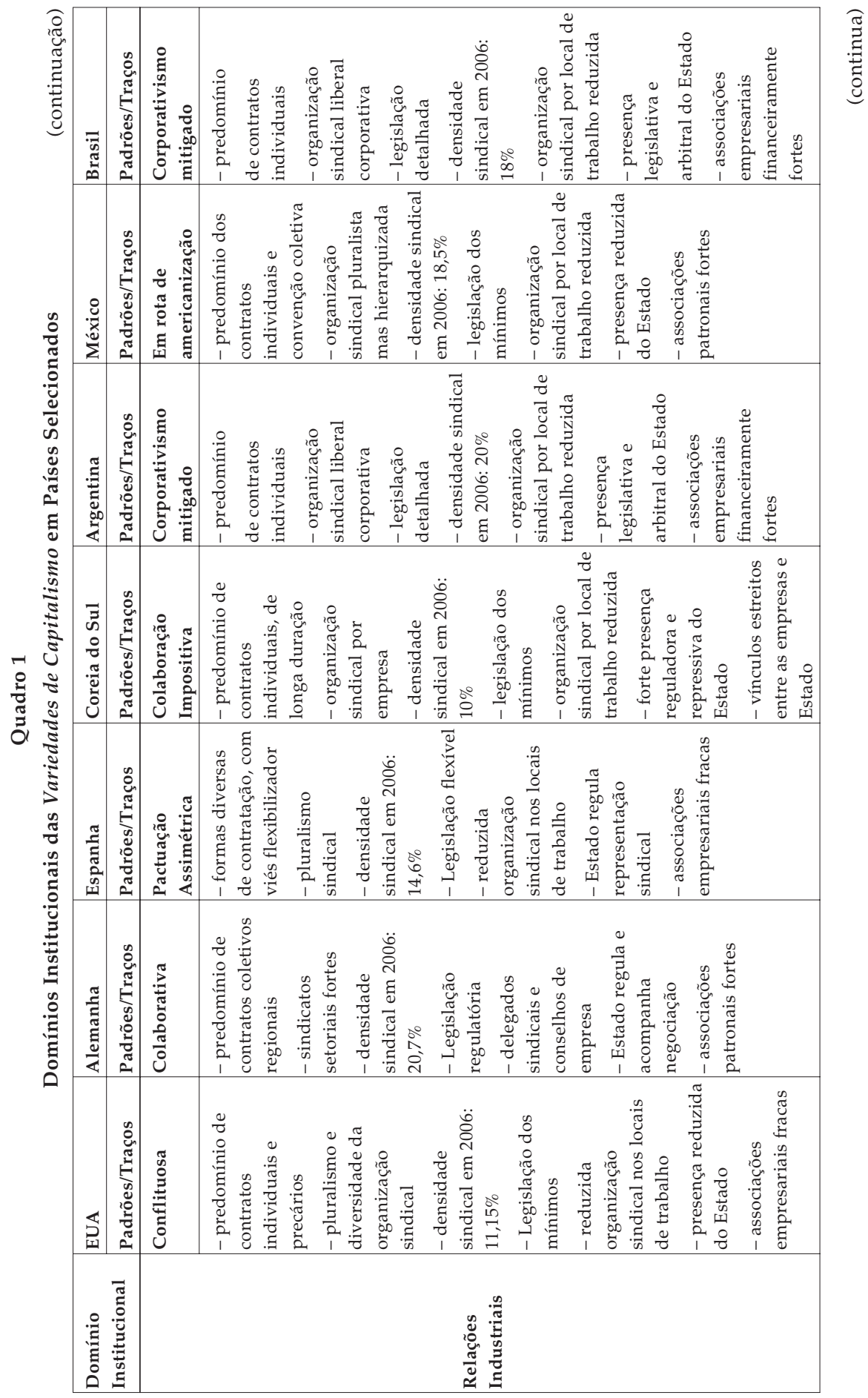


Ignacio G. Delgado, Eduardo S. Condé, Angelo B. Ésther e Helena da M. Salles

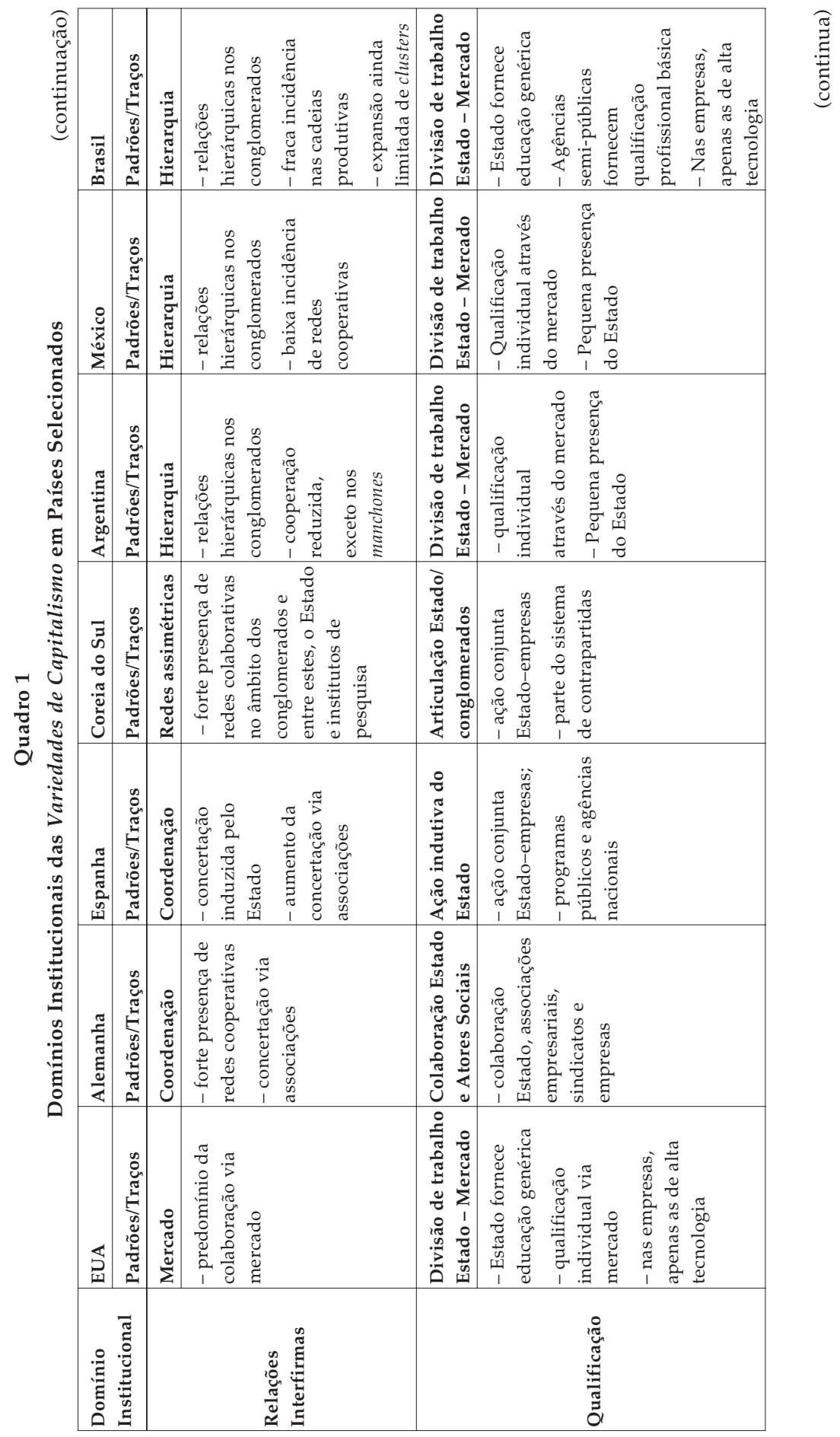


Cenários da Diversidade: Variedades de Capitalismo e Política Industrial...

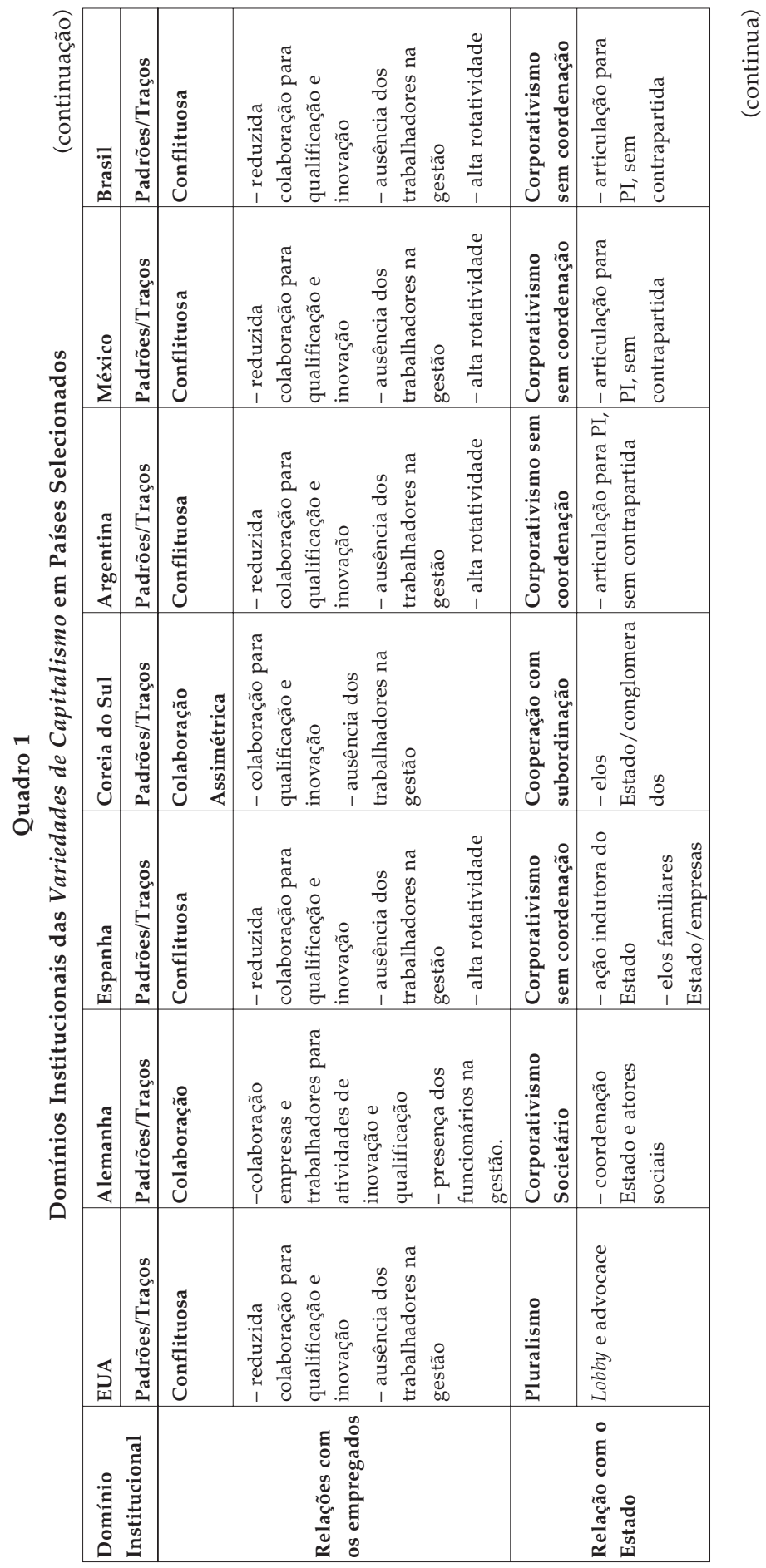


Ignacio G. Delgado, Eduardo S. Condé, Angelo B. Ésther e Helena da M. Salles

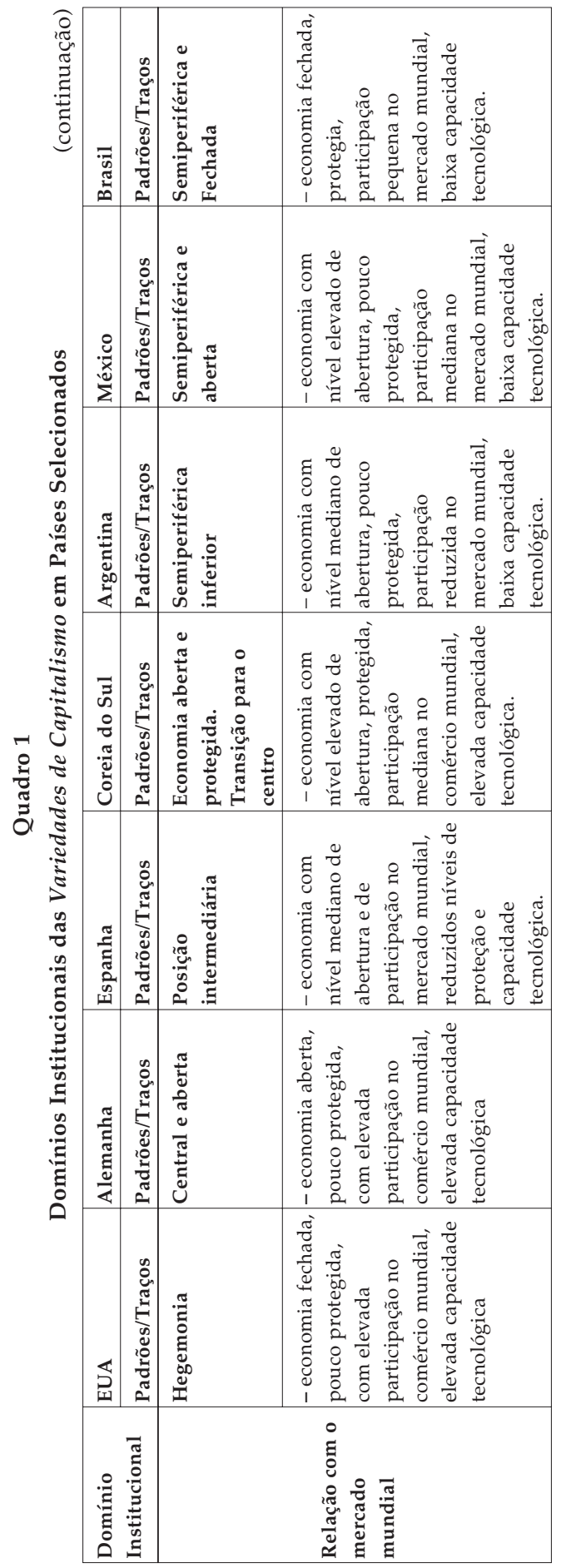


que políticas industriais orientadas para a mudança pretendem exatamente romper com tais situações de equilíbrio rebaixado, exigindo formas de coordenação ex ante (Delgado, 2005; 2009; Suzigan e Furtado, 2005).

Políticas industriais orientadas para processos de equiparação buscam fortalecer ou internalizar atividades econômicas que dispõem de pequena relevância nos países de desenvolvimento retardatário, reconhecidas como fundamentais à dinâmica econômica moderna, identificada àquela que se processa nas economias capitalistas centrais. Seus mecanismos foram, classicamente, a adoção de tarifas protecionistas, crédito subsidiado, indução pública do investimento, de modo a assegurar a edificação de setores industriais inteiros, por via da alteração dos preços relativos e da redução da incerteza dos investimentos privados. O problema a considerar é se tais políticas são adequadas à elevação da competitividade em escala global, associada à redução da proteção dispensada aos mercados internos nacionais e elevação da mobilidade internacional dos capitais.

Neste cenário é que a elevação da competitividade das empresas, a partir da acentuação de sua capacidade de inovar, ganha relevo. Mesmo tomando a inovação em um sentido amplo - isto é, envolvendo novas combinações de modo a gerar produtos e processos diferenciados, sem, necessariamente, associar-se à criação de uma nova tecnologia -, a acentuação da capacidade de inovação das firmas é inseparável da elevação dos dispêndios em pesquisa e desenvolvimento e de sua capacidade de gerar internamente novas combinações, a partir de conhecimentos amplamente disponíveis e daqueles que acumula em sua própria experiência e trajetória.

O dilema da ação estatal é, pois, não só criar as condições adequadas para a inovação, no sentido da expansão e da formação de recursos e da infraestrutura necessárias a esta, mas também definir os estímulos adequados a cada contexto para que as diferentes empresas venham a se valer dos recursos humanos e da infraestrutura de inovação, estabelecendo a atividade inovativa como parte de sua estratégia competitiva (Delgado, Condé, Ésther e Salles, 2009a). Ademais, cabe ao Estado desenvolver ações antecipadoras, que fortaleçam setores e atividades expressivos das tendências mais recentes e futuras do desenvolvimento tecnológico, de modo a evitar a exigência da busca perene do emparelhamento, combinando, pois, ações horizontais e seletivas. Se a for- 
mação de recursos humanos e a criação de uma infraestrutura adequada à inovação são indispensáveis para que esta possa vir a se processar de forma generalizada, o desenvolvimento de determinados setores é indispensável também para isto, ou mesmo para a perspectiva de ocupação de posições competitivas no futuro, como é o caso, respectivamente, do setor de informática ou da nanotecnologia. Por fim, em que pese a centralidade da inovação como objetivo das políticas industriais, não pode o Estado deixar de lado outros objetivos, como o crescimento econômico, a preservação do nível de emprego, a sustentabilidade ambiental do desenvolvimento.

O desenvolvimento das modernas políticas industriais exige, ainda, mais duas condições complementares. A primeira é a presença de formas de articulação entre o Estado e o empresariado que assegurem a fixação de metas, a colaboração e a confiança recíprocas para a condução efetiva das políticas industriais (Evans, 1993; Delgado et alii, 2009b). A segunda é a preservação da estabilidade institucional, de marcos regulatórios favoráveis às inversões privadas e a presença de um ambiente macroeconômico pró-investimento. Não se trata, aqui, importa ressaltar, de estabelecer formas precárias de contratação da força de trabalho para assegurar o crescimento econômico, correlação baseada numa crença repetida à exaustão no fim do século passado. Na verdade, o contrário é que tende a prevalecer, quando se trata de combinar crescimento econômico com aumento da capacidade de inovação das empresas (Delgado et alii, 2009a; 2009e). Trata-se de garantir condições institucionais e macroeconômicas para assegurar estímulos ao investimento e certa imunidade das economias nacionais diante das flutuações derivadas da intensa mobilidade internacional dos capitais, além de mecanismos que assegurem a participação de diferentes atores no processo de inovação.

Abaixo apresentamos as proposições de política industrial e de inovação, de caráter geral, levadas adiante pelos países considerados neste estudo.

\section{Estados Unidos}

Nas políticas industriais desenvolvidas pelos EUA, é notável a ênfase na regulação do direito de propriedade. O Estado participa, ainda, no financiamento da pesquisa em diversas áreas, com destaque para o setor militar e de energia ${ }^{13}$. As compras governamentais, contudo, apare- 
cem como instrumento decisivo da política industrial. Embora não exclusivo das economias liberais, tal instrumento é, de fato, a principal forma liberal de intervencionismo estatal, que se realiza por meio de mecanismos de mercado, na ausência de condições favoráveis à coordenação entre os agentes econômicos por via de arranjos de natureza institucional.

Os EUA sempre desempenharam um papel de grande importância na produção científica e tecnológica, sobretudo pelos gastos governamentais, nas universidades e nas empresas. Ainda que hoje sob forte concorrência, dado o papel desempenhado no campo tecnológico por Coreia do Sul, Alemanha e China, os EUA permanecem entre os países líderes. O grande investimento tecnológico realizado pelas empresas é o destaque, mas as administrações federais não são passivas. O Instituto Nacional de Standards e Tecnologia (NIST) tem um importante papel por ser uma agência federal que opera junto ao Departamento de Comércio. Ele possui laboratórios, um programa nacional de qualidade, uma rede nacional de apoio para pequenas indústrias e um programa de inovação tecnológica (TIP), este no apoio a indústrias, universidades e organizações de pesquisa sem fins lucrativos, com valores importantes de investimento. Em resumo, um tripé importante: as empresas, os fundos de investimento em P\&D do governo central e a ênfase no tema do "ambiente adequado", a exemplo das patentes e a definição de nítidos marcos regulatórios, como o incentivo às empresas.

O documento Tecnologia para o Crescimento Econômico da América - Uma Nova Direção para a Construção do Fortalecimento Econômico (1993), sob o governo Clinton, é uma importante referência de orientação geral sobre políticas de inovação e tecnologia. Seu objetivo é incrementar a competitividade para o crescimento da indústria, dos trabalhadores e consumidores, promover inovação e competitividade industrial, defender a propriedade intelectual e manter a liderança em tecnologia, ciência e matemática. Defende o fortalecimento da ciência básica e a ampliação do papel dos laboratórios estatais, sob fiscalização do Conselho Nacional de Ciência e Tecnologia (NSTC). O intento é fortalecer as relações com o setor privado, incluindo o investimento em alta tecnologia, redesenhando o papel do investimento federal em P\&D e ampliando o link pesquisa-indústria.

O período de George W. Bush na Casa Branca apresentou ênfase diferenciada. O impacto dos ataques terroristas de 2001 operou uma infle- 
xão para algumas áreas mais diretamente vinculadas ao rótulo de "defesa". Para o orçamento de 2002 foram incluídos gastos de US $\$ 1,5$ bilhão para a luta contra o bioterrorismo e a defesa doméstica, com todas as agências ligadas a P\&D recebendo recursos adicionais (US\$103 bilhões de gasto federal total). A preocupação antiterrorismo incentivou iniciativas nacionais de ciência e tecnologia, como a Iniciativa Nacional de Nanotecnologia, que associa dez departamentos federais com empresas envolvidas nesta linha. As pequenas e médias empresas recebem programas federais de Pesquisa e Inovação em Pequenos Negócios (SBIR) e da Transferência de Tecnologia em Pequenos Negócios (SBTT). Este programa foi reautorizado em 2008.

Os instrumentos básicos para as políticas indicam três iniciativas multiagências: ciência em nanoescala, engenharia e iniciativa em tecnologia. A estrutura de financiamento para a pesquisa acadêmica recebe apoio federal, mas incentiva a competição entre os pleiteantes. Da mesma forma, há uma defesa direta, pelo governo, de que os investimentos em pesquisa básica estejam concentrados na Fundação Nacional de Ciência (NSF). Em 2006, é lançada a Iniciativa para a Competitividade Americana. A maior atenção é dada ao investimento em P\&D, envolvendo as diferentes capacidades nacionais e o incremento da produtividade pelos setores da economia. Um dos instrumentos importantes para esta política foram as isenções fiscais para empresas investidoras em P\&D.

Os instrumentos gerais para a consecução da política científica e tecnológica envolvem o crédito tributário e o incentivo ao investimento privado, mas também é indicada a necessidade do investimento em professores de física, matemática e ciências da educação e no incentivo aos programas para a competitividade e produtividade fabril. A NSF passaria a operar como a principal agência para promover áreas científicas.

O Departamento de Comércio desenvolveu um plano estratégico (2007-2012) neste campo. O Programa para Administração de Tecnologia enfatiza a cooperação interagências, como a Administração Nacional para os Oceanos e a Atmosfera (NOOA), a Administração Nacional de Telecomunicações e Informação (NTIA, telecomunicações e internet), o Escritório de Indústria e Segurança (BIS, para exportação de tecnologia) e a Administração para o Comércio Internacional (ITA, para 
tecnologia compartilhada). O NIST é o articulador entre agências, o setor privado e os laboratórios de pesquisa.

Basicamente, há uma grande preocupação com o tema da propriedade intelectual, que defende uma ação forte contra as empresas envolvidas com a "pirataria", a capacitação de inovadores para proteger seus direitos, o trabalho juntamente com a indústria, e a busca de apoio de parceiros comerciais dos norte-americanos. Os republicanos são refratários a uma política industrial ativa, preferindo que as empresas tenham seu link com o Estado pela via de créditos tributários e incentivos às melhorias para a produtividade. Menos iniciativa estatal e, enfim, mais "ambiente favorável" e pesquisa básica.

\section{Alemanha}

Os diferentes e múltiplos programas estabelecidos e desenvolvidos nos últimos anos na Alemanha replicam várias dimensões próprias da tradição consociativa do país, ao buscarem a articulação de institutos de pesquisa, universidades e empresas. O governo da Alemanha tem a educação e a pesquisa como alta prioridade, fazendo investimentos constantes e crescentes nessas áreas, com o objetivo de aumentar a eficiência e a inovação da ciência alemã. Para o período de 1998 a 2008, vários programas foram desenvolvidos. Em termos gerais, observa-se que o governo alemão tem como objetivo central eliminar as barreiras entre pesquisa pública e iniciativa privada, tornando atraentes as transferências entre uma e outra. Para isso, o governo e as länder decidiram avaliar as instituições que financiam conjuntamente a fim de assegurar e melhorar a qualidade do sistema de financiamento da pesquisa. Ressalta-se, nesse contexto, o papel primordial assumido pelos institutos de pesquisa e universidades, que passam a atuar, enfaticamente, em parceria com as pequenas e médias empresas. Paralelamente, o governo procura mais flexibilidade e desempenho com o emprego e as estruturas de remuneração para o ensino superior e as instituições de pesquisa não-universitárias.

No período de governo do Chanceler Gerard Schröder (1998 a 2005) alguns programas merecem destaque. O Industrielle Gemeinschaftsforschung visa a apoiar as PMEs -Pequenas e Médias Empresas - da ex-Alemanha Oriental, tendo a iniciativa ZuTech ("Futuro de Tecnologias para Pequenas e Médias Empresas") para financiar o desenvolvimento de soluções para a renovação estrutural da economia baseada 
em tecnologias de maior valor, além dos Competence Centres to Support Small and Medium-sized Enterprises (programa de três anos de consultoria e de informação, especialmente para as PMEs no domínio do comércio eletrônico).

Em 1999, destacam-se os programas de cooperação em pesquisa (Forschungskooperation) envolvendo as PMEs e os institutos de pesquisa. É dada, também, continuidade ao programa FUTOUR, para promoção e apoio da tecnologia orientada para abertura de novos negócios nas novas länder da Alemanha. O InnoRegio - Innovative Stimuli for Region (InnoRegio - Innovative Impulse für die Region) orienta-se, do mesmo modo, para ao apoio às novas länder. Criam-se, ainda, redes regionais temáticas de apoio ao arranque e crescimento de empresas inovadoras EXIST - PUSH! (Stuttgart) e KEIM (Karlsruhe/Pforzheim).

Em 2000, o programa de financiamento Microsystem Technologies 2000 + (MST 2000 +, cuja duração abrange o período 2000-2003) foi instituído com o fito de estabelecer uma ampla base de know-how tecnológico na indústria e na ciência. Destaca-se, também, o PROgramm INNOvation-competence of medium-sized enterprises (PROINNO), iniciado pelo BMWi (Ministério da Educação e Tecnologia), que apoia a P\&D e a cooperação das PMEs para a inovação de produtos, processos e serviços.

Em 2001, destaca-se o Framework Programme Biotechnology - Using and Shaping Opportunities, para apoiar o programa de biotecnologia, além de recursos disponibilizados para o National Genome Research Network. No campo da tecnologia de informação (TI), o programa do governo Innovation and Jobs in the Information Society of the $21^{\text {st }}$ Century define o curso para a construção da chamada sociedade baseada no conhecimento.

Em 2004, cria-se a Excellence Initiative (promoção da excelência e pesquisas acadêmicas de alto nível em universidades), e o Pact for Research and Innovation (aumento do financiamento institucional para as instituições públicas de pesquisa não universitárias que recebem apoio do Governo Federal - Max Planck Society, da Sociedade Fraunhofer, Helmholtz-Centres, Leibniz Association - em 3\% ao ano, até 2010).

Em 2005, promove-se a expansão do programa EXIST, através da submedida, EXIST Seed, de uma escala regional para o âmbito federal. No outono de 2005, um novo subprograma no âmbito do programa de bio- 
tecnologia foi lançado, o EXIST Goes Bio, que oferece financiamento para o arranque da pesquisa pública de biotecnologia.

Devido ao aumento das despesas de P\&D pelo setor empresarial, a participação dos gastos públicos no financiamento de $\mathrm{P} \& \mathrm{D}$ diminuiu nos últimos anos. O financiamento público de $\mathrm{P} \& \mathrm{D}$ em organizações públicas de pesquisa tende a se deslocar para o financiamento baseado em projetos. Consequentemente, há um vasto leque de instrumentos da política de inovação na Alemanha, que envolvem a política fiscal, a política de concorrência, a simplificação dos procedimentos burocráticos, além da política científica, que prevê vários financiamentos (empréstimos, garantias, subsídios de capital) e as medidas de sensibilização orientadas às empresas. Como resultado, não há quase nenhuma categoria de plano de ação sem uma medida de ação. Uma exceção notável é a área de incentivos fiscais, que não são aplicados na Alemanha como uma forma de estimular os investimentos de P\&D das empresas.

Atualmente, o governo alemão pretende alcançar o objetivo da Agenda de Lisboa para a União Europeia, que prevê 3\% do PIB investido em P\&D em 2010. Em resumo, o governo alemão está tentando incrementar o objetivo mais amplo de criar condições sustentáveis para fomentar a inovação e o progresso tecnológico, especialmente para promover a capacidade inovadora das pequenas e médias empresas. Dentre as principais políticas de apoio à inovação, destaca-se a High-Tech Strategy do governo federal (lançado em 2006, no governo da chanceler Angela Merkel), que é uma estratégia nacional que abrange todos os ministérios. Estabelece estratégias para dezessete "campos de futuro" e pretende traduzir ideias de tecnologias básicas o mais rapidamente possível em produtos comercializáveis, serviços e processos. Em fevereiro de 2008, o governo federal lançou uma estratégia de internacionalização para atrair pesquisadores, estudantes e investimento estrangeiro, com um forte foco em P\&D. No âmbito da Initiative for Excellence, a Alemanha está oferecendo financiamento de projetos de apoio às escolas de pós-graduação, "clusters de excelência" e de pesquisa de ponta nas universidades. Várias novas políticas visam taxas de graduação superior, incluindo o Higher Education Pact 2020, e o Qualifications Initiative.

O governo federal também está introduzindo uma nova política de inovação contínua, sob a forma do Six Billion Euro Programme e do High-Tech Strategy. Como um elemento importante da sua política de 
inovação, está investindo seis bilhões de euros adicionais em projetos de pesquisa $P \& D$ durante este período legislativo. Estes fundos adicionais são destinados a projetos que prometem ter um grande efeito de mobilização para a inovação e os mercados futuros.

Por meio do programa PROINNO II, o Ministério da Economia apoia a cooperação de investigação cross-border entre empresas alemãs e estrangeiras e instituições de pesquisa. Um suporte similar está disponível para projetos realizados no âmbito da iniciativa EUREKA para promover a inovação europeia, que inclui também os países da União Europeia (UE).

Por fim, por via de uma série de outras medidas, que se somam às indicadas anteriormente, o governo alemão está reagindo ao fato de que os investimentos em $\mathrm{P} \& \mathrm{D}$ por parte da indústria estão se tornando cada vez mais dependente da evolução econômica. Os especialistas têm observado que as empresas estão se retirando da pesquisa a longo prazo. Em vez de tomar partido de pesquisa estratégica para a abertura de novos mercados, elas estão adquirindo novas competências por meio da terceirização de pesquisa ou de compra de resultados de pesquisa - incluindo os resultados da pesquisa financiada por fundos públicos. A pesquisa financiada publicamente, assim, torna-se mais importante.

\section{Espanha}

A Espanha reedita, a cada quatro anos, planos abrangentes sujeitos à coordenação de conselhos intragovernamentais e abertos à cooperação com os atores sociais relevantes na ordem econômica e nas atividades de inovação. Prevalecem as políticas de perfil horizontal e a busca da criação de um ambiente adequado à inovação, de efeito incerto no estímulo ao gasto privado com inovação, não obstante os instrumentos diversos mobilizados, desde medidas de assistência técnica, formação, incentivos fiscais, financiamento público. Os expressivos índices de investimento e de crescimento do produto industrial exibidos pelo país no início do século contrastam com o êxito acanhado da política de inovação, que têm resultado num crescimento modesto das atividades inovadoras, preponderantes em setores de menor significação econômica e, em boa parte, lideradas pelo Estado e por residentes estrangeiros. Se é possível aí identificar um padrão, ele só tem equivalência com o México - também incluso num processo de absorção crescente de sua economia nacional a um espaço mais amplo, embora em posição de 
grande subalternidade -, mas, até o momento, não é possível afirmar que dispõe de potencialidade para reverter a posição intermediária ocupada pelo país no que se refere à inovação.

A política industrial da Espanha vem sendo desenvolvida pela Comissão Interministerial de Ciência e Tecnologia, quando assumiu a presidência do país José Maria Alfredo Aznar López, em 1996. O documento em que está consubstanciada a política é o chamado Plano Nacional I+D (Plano Nacional de Investigação Científica Desenvolvimento e Inovação Tecnológica), que continua sendo elaborado pelo governo atual de Zapatero (2004-). O PN original foi criado em 1988, com a aplicação da Lei de Fomento e Coordenação Geral de Investigação Científica e Técnica (1986) - Lei da Ciência - que é revisto a cada quatro anos.

O governo espanhol entende que a competitividade internacional deve ser baseada em áreas de grande dinamismo associadas ou baseadas no conhecimento, que geram inovações tecnológicas, as quais devem, de forma rápida e eficiente, ser convertidas em produtos comercializáveis. Além disto, tem assinalado que embora a empresa seja o agente que cristaliza a inovação, a competitividade é resultado de múltiplas interações de agentes diversos, tais como os grandes grupos empresariais, as PMEs, os centros técnicos, os centros públicos de pesquisa ou de inovação (CPI), os administradores e clientes, as entidades financeiras e os poderes públicos. Deste modo, o PN destaca quatro entornos fundamentais: científico, tecnológico, produtivo e financeiro.

Os programas setoriais são coordenados basicamente pelo Ministério da Educação e Ciência e outros órgãos. A coordenação interterritorial é realizada pelo Conselho Geral de Ciência e Tecnologia. Finalmente, os fundos estruturais da Uniao Europeia têm se mostrado um instrumento eficaz de cooperação entre o Estado e as Comunidades Autônomas. Além disto, o PN é financiado pelo Fundo Nacional (Fondo Nacional), dentro do qual foi criado o Programa Nacional de Fomento da Articulação do Sistema Ciência-Tecnologia-Indústria (PACTI).

A partir do PN I+D 2000-2003, a inovação é incorporada como tema e valor central. Assim, o plano passou a se chamar Plano Nacional de Investigação Científica, Desenvolvimento e Inovação Tecnológica. A diferença, na prática, é que se passa a compreender de forma articulada todas as ações de pesquisa e desenvolvimento, desde a pesquisa básica até a inovação tecnológica, envolvendo todos os ministérios com- 
petentes em P\&D. Além disso, ressalta-se a criação, em 2000, do Ministério da Ciência e Tecnologia (MCYT).

O PN é estruturado em torno de três eixos complementares: eixo temático (áreas prioritárias e suas linhas temáticas); eixo instrumental (modalidades de participação dos diversos agentes do sistema de ciência-tecnologia-empresa e os instrumentos financeiros correspondentes); e o eixo orçamentário (cenário econômico). É abrangente e leva em conta a atuação da UE - especialmente o V Programa Marco de P\&D (V PM) e aquelas financiadas pelos fundos estruturais, bem como as iniciativas das comunidades autônomas através de seus planos regionais e equivalentes.

Todas as ações previstas no PN estão associadas a uma modalidade de participação prevista na legislação espanhola de acesso a crédito. Os mecanismos financeiros podem ser subvenção total ou parcial, subvenção simultânea, associada a um crédito, crédito reembolsável, refinanciamento de crédito, participação em capital (fondos de arranque) para fomentar a abertura de empresas de base tecnológica, e fundos de investimento mútuo (fondo de coinversión) para consolidar empresas de base tecnológica. Ainda no que tange ao aspecto financeiro, o PN assume que o setor privado é o grande responsável pelas atividades de $\mathrm{P} \& \mathrm{D}$, devendo aumentar, portanto, seus investimentos nesse campo.

Em outubro de 2005, o governo aprovou o chamado Programa Nacional de Reformas (PNR), que consiste na resposta espanhola ao relançamento da Estratégia de Lisboa, estabelecendo como objetivo estratégico a plena convergência com a União Europeia até 2010, tanto no que diz respeito à renda per capita, quanto em emprego e sociedade do conhecimento. Atualmente, são definidas quatro grandes áreas no PN: geração de conhecimentos e capacidades; fomento à cooperação em P\&D; desenvolvimento e inovação tecnológica setorial; ações estratégicas.

Destacam-se duas situações. A primeira, em relação à área de geração de conhecimentos e capacidades, é a criação do programa Severo Ochoa, cujo objetivo é incorporar aos centros nacionais pesquisadores de renome internacional que desenvolvem suas atividades num centro de excelência. Além disso, introduz-se o mecanismo de financiamento, o Programa Nacional de Fortalecimento Institucional, ligado a objetivos de excelência tecnológica e científica. A segunda, relacionada à área de fomento à cooperação em $\mathrm{P} \& \mathrm{D}$, pretende eliminar a principal 
debilidade do sistema, que é cooperação escassa entre agentes de diferentes naturezas, sobretudo entre empresas e as universidades e centros públicos de pesquisa, tanto em âmbito nacional quanto internacional.

Por fim, o PN aposta na simplificação das estruturas de gestão, racionalizando e integrando instrumentos existentes, criando novos e eliminando outros, quando for o caso, tendo como foco a participação plena das comunidades autônomas.

\section{Coreia do Sul}

A Coreia do Sul é, definitivamente, um caso especial. Dotada de um Executivo forte e de organizações empresariais lideradas pelos principais grupos industriais, o país tem revelado uma grande capacidade de estabelecer metas e objetivos em suas políticas, bem como de responder com agilidade aos desafios que as situações de crise lhe impõem, lidando com um repertório variado de política industrial. Não obstante as medidas de desregulamentação econômica vividas nas últimas décadas e das tentativas de conter o poder dos conglomerados, a Coreia mantém sua tradição de formular políticas com metas de longo prazo, envolvendo as empresas nos organismos públicos de formulação e implementação, preservando os mecanismos de contrapartida. A Coreia do Sul é um dos mais exemplares saltos de crescimento no setor de $P \& D$ entre todos os países, com o investimento em inovação como proporção do PIB maior que todos os países analisados, sendo que é elevada a participação das empresas neste esforço. O investimento em pesquisas aplicadas, e em relação direta com as plataformas de exportação e desenvolvimento industrial, conduziu o próprio investimento governamental à aplicação mais direta em pesquisa básica. Entretanto, é verdade que a maioria das patentes de alta tecnologia é menos expressiva do que em outros países, como os EUA ou Alemanha.

A própria estrutura do governo mostra a preocupação coreana com o tema, dados os ministérios envolvidos - Educação, Ciência e Tecnologia, Economia do Conhecimento, Comunicação; quatro escritórios associados ao tema, vinculados ao segundo vice-ministro de Educação, Ciência e Tecnologia (Ciência e Tecnologia, Política de Pesquisa Acadêmica, Energia Atômica e Cooperação Internacional). A ênfase governamental está localizada na preocupação com pesquisas em biotecnologia, nanotecnologia e software, com fundos governamentais específi- 
cos. Em 1997 foi promulgada a Lei Especial de Ciência e Tecnologia em Inovação, englobando a criação do Conselho Nacional de Ciência e Tecnologia (NSTC), estruturado a partir da cooperação interministerial entre Ciência \& Tecnologia e Educação. Foi estabelecido um Plano para Inovação em Ciência e Tecnologia, a ser desenvolvido em cinco anos. O documento detalhando a "Estrutura Geral da Política" indica a intenção de ampliar competências nas áreas tecnológicas para o desenvolvimento de um sistema de inovação adequado à competição. É enfatizada a relação indústria/universidade e a pesquisa universitária como infraestrutura-base de investigação, incluindo a criação de novos centros de pesquisa e melhoria da própria pesquisa. Têm destaque a engenharia de base tecnológica, a tecnologia de informação e a biotecnologia, complementadas pelo programa de reforma universitária "Brain Korea 21" (BK21), voltado para a pesquisa com mais qualidade e a pós-graduação de excelência.

A ação coreana envolve uma política fiscal forte. Se as empresas aumentarem o investimento em P\&D em 50\% (nos últimos quatro anos), podem realizar dedução de até $5 \%$ do investimento total em equipamentos e instalações ou no desenvolvimento de recursos humanos. Empresas baseadas em P\&D recebem dedução em relação ao imposto sobre consumo, bem como engenheiros e cientistas estrangeiros, nesta área, têm isenção de imposto sobre a renda. São isentas de imposto as operações de transferência de direitos de propriedade intelectual, sendo também passíveis de crédito fiscal as doações realizadas para entidades governamentais ligadas à pesquisa. É previsto, ainda, o financiamento para novas ideias que promovam teste do produto e/ou comercialização de novas tecnologias.

A preocupação com políticas contínuas entre governo, universidades e empresas é uma constante. A Lei de Ciência e Tecnologia (2001) define prioridades em C\&T e P\&D, particularmente biotecnologia, bioindústria e nanotecnologia. Iniciou-se o programa Fronteira do Século XXI em $\mathrm{P} \& \mathrm{D}$ para, em dez anos, desenvolver um núcleo tecnológico relacionado a dez projetos em nanotecnologia, biotecnologia, novos materiais e tecnologia ambiental, estruturado por consórcio público-privado (US\$ 8 milhões por ano durante dez anos). Está em desenvolvimento uma Visão de Longo Prazo para Ciência e Tecnologia, com horizonte até 2025. O Ministério do Comércio, Indústria e Energia ganhou relevo particularmente após as determinações governamentais relativas às reformas internas nas empresas e no setor financeiro (1997). Suas ações 
envolveram medidas para ampliar a competitividade e fortalecer o investimento externo. No setor industrial foram tomadas medidas saneadoras e de reestruturação das companhias, a defesa de uma produção ambientalmente amigável, o estímulo ao $e$-commerce, às pequena e média empresas, a privatização de companhias estatais e ao fortalecimento da rede infraestrutural. Investimento em pesquisa básica e em recursos humanos qualificados, bem como a maior concentração de investimentos em tecnologias selecionadas, são outros pontos importantes. $\mathrm{O}$ governo identificou dez setores relevantes: TV digital, displays (LCD, LED, PDP), robôs, automóveis de nova geração, semicondutores, telefones móveis, soluções digitais, novas tecnologias de armazenamento (baterias), biomedicina e home network.

A ação governamental incorporou ao NSTC dirigentes industriais, associando interesses da indústria ao sistema nacional de C\&T e P\&D. São mantidos fundos públicos destinados às firmas associadas a $P \& D$, disponibilizando recursos para empréstimos e participação pela via de projetos (para produção, por contrato, por subvenções), incluindo-se, ainda, o estímulo à competitividade entre as próprias firmas. Para as pequenas e médias empresas podem ser concedidos financiamentos adicionais para pesquisa e inovação e existe a intenção de promover fundos de capital de risco e apoio para novas empresas de base tecnológica. Como importante adição às políticas, o governo propõe reformar regras de propriedade e licenciamento intelectual oriundas de financiamento público, criando incentivos adicionais para determinados tipos de invenção (como genética, software, inovações nos negócios) e fortalecer os direitos de propriedade intelectual por meio de cortes especializadas.

\section{Argentina}

A Argentina não tem uma tradição de inovação tecnológica, em parte dado o predomínio da política de substituição de importações em seu processo de desenvolvimento. As políticas de corte neoliberal do governo Menem (1989-1999), contudo, acentuaram as dificuldades reveladas pelo país para dotar-se de uma estrutura produtiva centrada na inovação. Boa parte das políticas industriais desenvolvidas de 1998 até os dias de hoje adotam como principais instrumentos medidas de isenção tributária e assistência técnica.. As dificuldades fiscais inibem iniciativas voltadas para o financiamento do investimento e/ou as compras governamentais. 
No governo Menem (1989-1999) foi criado em 1996 um programa de incentivo às pequenas e médias empresas, o Regime de Bonificação de Taxas de Juros. O objetivo era facilitar o acesso das PYMEs - Pequenas e Médias Empresas - ao crédito dos bancos que participavam do programa, mediante um subsídio do governo para as taxas de juros praticadas. Tal financiamento cobria desde a constituição de capital de giro dessas empresas até a aquisição de bens de capital e o investimento em inovação tecnológica. Ainda com o foco nas PYMEs, foi criado, no mesmo governo, em 1997, o Programa de Reestruturação Empresarial (PRE), por meio do qual as empresas obtêm empréstimos a fundo perdido para o acesso a serviços profissionais e assistência técnica.

Ainda no período Menem, no âmbito de uma reforma do sistema de Ciência e Tecnologia da Argentina, foram criados, em 1996, a Agência Nacional de Promoção Científica e Tecnológica e o Gabinete Interministerial de Ciência e Tecnologia (GAGTEC). Os setores privilegiados pela Agência foram a metalurgia, a biotecnologia, as energias alternativas, as TICs (tecnologias de informação).

No governo De La Rúa (1999-2001) foi criado o programa Regime de Importação de Linhas de Produção Usadas e Novas, iniciado em 2000 e encerrado em 2008, destinado às empresas exportadoras, com o objetivo de aumentar os investimentos na competitividade dos produtos industrializados. É também deste governo o Regime de Incentivos para a produção dos Bens de Capital, de 2001, para estimular a fabricação nacional de bens de capital, informática e telecomunicações, através de abono fiscal.

No governo Duhalde foi criado, em 2002, o programa Rede de Agências de Desenvolvimento Produtivo, com mais de setenta agências distribuídas pelo país, para assistência técnica e financeira às pequenas e médias empresas, envolvendo parcerias público-privado e cofinanciamento entre governo federal, províncias e municípios.

No governo de Nestor Kirchner foi elaborado, em 2006, o PMT3 (Programa de Modernização Tecnológica), com o objetivo de formar recursos humanos para o setor público, com recursos do BID e do próprio governo. Foram priorizados os setores de combustíveis, metalurgia, saúde, software, nanotecnologia e biotecnologia.

Ainda nesse governo foi criado, em 2007, o Programa de Apoio à Indústria de Software e Serviços Informáticos, visando a melhorar o 
padrão de qualidade dentro das indústrias por meio de assistência técnica e crédito a taxas subsidiadas. Também é do governo Nestor Kirchner o programa Fomento à Pequena e Média Empresa, de 2007, que, além da assistência técnica e apoio financeiro, busca auxiliá-las em sua integração internacional, com o desenvolvimento de negócios de exportação.

Cristina Kirchner também elegeu como prioridade o apoio às pequenas e médias empresas. É de seu governo o Regime de Promoção de Investimentos em Bens de Capital e Obras de Infra-Estrutura, de 2008, que visa o crescimento econômico e a geração de empregos e utiliza-se de benefício fiscal, a isenção de Imposto sobre o Valor Agregado (IVA). Além disso, foi criado, também em 2008, o programa Formulação e Aplicação de Políticas para a Indústria, para melhorar a competitividade da indústria nacional, mediante a especialização industrial e consequente obtenção de produtos com alto valor agregado. Finalmente, ao governo de Cristina Kirchner deve ser creditada a criação, em 2008, do Conselho Nacional de Investigações Científicas e Técnicas (CONICET), para desenvolver todas as atividades relacionadas com o desenvolvimento científico e tecnológico do país.

\section{México}

No México, o incremento recente da participação das empresas nas atividades de inovação ocorre sem alteração de destaque na participação dos gastos com inovação no PIB. Até recentemente, os diversos programas do governo mexicano foram marcados pela perspectiva de criação de um ambiente institucional favorável ao investimento privado, com destaque para medidas regulatórias, além de programas de assistência técnica. Tal como na Argentina, prevalecem medidas de desoneração fiscal e tarifárias na política industrial. Nos governos de Vicente Fox e de Felipe Calderón Hinojosa ampliaram-se as fontes de financiamento, com o desenvolvimento, inclusive, de programas setoriais. Importa saber se terão efeito sem uma definição clara de contrapartidas estabelecidas para as empresas. O peso expressivo dos gastos com inovação efetuados por estrangeiros parece estar associado à crescente incorporação da economia mexicana ao NAFTA, mas não está claro qual é o seu impacto sobre a economia do país. Importante, de qualquer forma, é a sinalização para uma articulação entre as atividades portadoras de futuro e a indústria petrolífera, que pode criar processos de retroalimentação, desde que o Estado consiga impor à indústria do petróleo 
um conjunto de metas que a induza a preparar sua própria transição, no rumo de uma nova matriz energética.

No governo de Ponce de León (1994-2000), foi criado, em 1996, um Programa de Política Industrial e Comércio Exterior, com objetivos amplos e ambiciosos, como a melhora da infraestrutura física e base humana e institucional, estímulo à integração das cadeias produtivas, promoção de exportações, entre outros. A avaliação permanente de resultados e a interação do governo com produtores eram previstos pelo governo.

Quanto à política de melhoramento da infraestrutura tecnológica para a indústria, dois elementos são destacados - a modernização tecnológica e a promoção da qualidade -, e, para alcançá-los, foram planejados diversos arranjos institucionais.

No governo de Vicente Fox (2000-2006) foi elaborado o Programa de Desenvolvimento Empresarial 2000-2006, com objetivos que vão da criação de um ambiente econômico, jurídico e normativo propício ao desenvolvimento das empresas até objetivos mais específicos, como promover habilidades administrativas, laborais e produtivas etc. Para alcançá-los foram criados 151 programas de apoio do governo federal, dos quais uma fração expressiva (39) era de programas de capacitação, assistência técnica e consultoria empresarial, e, outra (30), de créditos e serviços financeiros.

O Plano Nacional de Desenvolvimento Industrial 2000-2006 propôs a criação de um Sistema Nacional de Indicadores para o acompanhamento dos resultados dos programas e esperava obter muitos resultados até 2006, entre eles o aumento da integração de insumos nacionais em cinco pontos percentuais para exportações manufatureiras não maquiladoras e em vinte pontos percentuais para as exportações da indústria maquiladora. Quanto ao desenvolvimento tecnológico, o governo Fox propôs o Programa Especial de Ciência e Tecnologia de 2001-2006, que tinha como objetivos criar uma política de Estado de valorização da C\&T, aumentar a capacidade científica e tecnológica, promover a competitividade e a inovação das companhias. Em 2002, a nova Lei de Ciência e Tecnologia regulamentou a área. Os setores priorizados foram a tecnologia da informação, a eletrônica e telecomunicações, a saúde (remédios, sistemas de diagnósticos, materiais e equipamentos), a agricultura, a pesca e alimentação, a energia e a construção civil. 
No governo de Calderón Hinojosa, ainda em curso, foi formulado o Plano Nacional de Desenvolvimento para 2006-2011, que inclui, entre seus objetivos, promover a criação, desenvolvimento e consolidação das micro, pequenas e médias empresas (MIPyMES). A Secretaria de Economia criou dez programas de apoio empresarial. Em relação ao desenvolvimento tecnológico, o governo criou o INNOVAPYME, o PROINNOVA e o INNOVATEC. Os setores priorizados pelo INNOVAPYME são as micro, pequenas e médias empresas; pelo PROINNOVA, as Associações ou redes entre empresas, Instituições de Ensino Superior e Centros de Pesquisa; pelo INNOVATEC são as empresas inovadoras de todos os tamanhos. Além disso, o governo criou o Comitê Nacional de Produtividade e Inovação Tecnológica (COMPITE), para dar consultoria e assistência técnica às empresas. $\mathrm{O}$ Programa para o Desenvolvimento da Indústria do Software (PROSOFT) aprova subsídios para programas da área.

\section{Brasil}

No Brasil, até 1999, o governo Fernando Henrique Cardoso manteve-se reticente à adoção de diretrizes de política industrial, não obstante a presença do documento, de 1996, Política Industrial, Tecnológica e de Comércio Exterior - Reestruturação e Expansão do Sistema Industrial Brasileiro, sob responsabilidade do Ministério da Indústria, do Comércio e do Turismo. O sentido geral da política proposta é a criação de um ambiente favorável à elevação da competitividade, por meio, principalmente, da eliminação do Custo Brasil, por via de correções no sistema tributário e regulatório e do desenvolvimento da infraestrutura. Destaca-se, ainda, a preservação da estabilidade econômica, "com regras claras e não discriminatórias", a modernização das relações trabalhistas, o "crescimento dos investimentos diretos estrangeiros", a integração das empresas brasileiras em redes internacionais. Por fim, "políticas específicas" são apontadas como relevantes, tão somente, para correção de "falhas de mercado".

Importa registrar, contudo, que, não obstante esta orientação geral, medidas pontuais de política industrial foram adotadas, em favor do setor automotivo, de softwares e de medicamentos. Por seu turno, ao final do segundo mandato de Fernando Henrique Cardoso, embora não exista um documento geral de orientação da política industrial, esta passa a fazer parte da agenda do governo, especialmente mediante a criação dos fóruns de competitividade e dos fundos setoriais. 
O governo Lula manteve a orientação macroeconômica de seu antecessor, assim como os fundos setoriais e os fóruns de competitividade, e reabilitou a perspectiva de um papel mais ativo do Estado na promoção do desenvolvimento, conferindo grande destaque à ideia de política industrial, bem como ao estabelecimento de mecanismos de intermediação do Estado com o empresariado. Tal perspectiva se revela já em 2003, com o Roteiro para Agenda de Desenvolvimento. Em março de 2004, as Diretrizes de Política Industrial, Tecnológica e de Comércio Exterior definem como linhas de ação básicas a inovação e desenvolvimento tecnológico, a elevação da inserção externa, a modernização industrial, a ampliação da capacidade produtiva e da escala de produção das empresas brasileiras, a definição de opções estratégicas, a saber, o desenvolvimento da indústria de semicondutores, de fármacos e medicamentos, de softwares e de bens de capital. No Acompanhamento da Política Industrial, Tecnológica e de Comércio Exterior (PITCE), de 2005, além das linhas de ação horizontais e das opções estratégicas presentes nas Diretrizes, apresentam-se como metas da PITCE o reforço das atividades portadoras de futuro, a saber, a biotecnologia, a nanotecnologia e a biomassa e outras fontes de energia renováveis. Para a coordenação das ações desenvolvidas foram criados o Conselho Nacional de Desenvolvimento Industrial e a Agência Brasileira de Desenvolvimento Industrial, pela Lei 11.080, de 30 de dezembro de 2004, embora o primeiro já operasse informalmente desde abril de 2004.

Considerada as opções mais amplas do governo Lula para o desenvolvimento, a ênfase conferida às exportações e inovação tecnológica aparecia como elemento subordinado, dentro da "estratégia de longo prazo" estabelecida no Plano Plurianual de 2004-2007, que fixava como objetivo a incorporação progressiva das famílias trabalhadoras ao mercado consumidor das empresas modernas. No segundo mandato do governo Lula, todavia, a ênfase nas exportações e na inovação permanece na Política de Desenvolvimento Produtivo (PDP) que, ao contrário da PITCE, não destaca setores a serem objeto preferencial das ações a serem desenvolvidas. A PDP é apresentada como uma política pragmática, que prevê medidas de "implementação imediata", com "metas factíveis". As metas-país para 2010 são a ampliação do investimento fixo, de 17,6\% do PIB, em 2007, para 21\%; a ampliação da participação das exportações brasileiras para 1,25\%, contra 1,18\% apurados em 2007; a elevação do gasto privado em PED de 0,51\% do PIB, em 2005, para 0,65\%, em 2010; a dinamização das MPEs, envolvendo a elevação em $10 \%$ do número de empresas exportadoras. Os destaques estratégicos da política seriam o 
fortalecimento da MPEs, a expansão das exportações, a integração produtiva com a América Latina e o Caribe, a integração com a África, a regionalização da produção e a produção ambientalmente sustentável. Por fim, os programas estruturantes para sistema produtivos seriam construídos a partir de estratégias diferenciadas que levam em consideração os estágios e as oportunidades para os diferentes sistemas, a saber, o alcance da liderança mundial, a conquista de mercados, a focalização, a diferenciação e a ampliação de acesso.

Apontam-se como instrumentos da política os instrumentos de incentivo fiscais e tributários, o poder de compra governamental e instrumentos de regulação. No âmbito das ações sistêmicas, a PDP destaca iniciativas como a elevação dos recursos para investimento e a redução do spread do Banco Nacional de Desenvolvimento Econômico e Social (BNDES) em suas operações de financiamento, medidas diversas de desoneração tributária, a ampliação das linhas de financiamento do BNDES para inovação, a simplificação de procedimentos administrativos, a integração da política às outras ações do governo, em especial as desenvolvidas pelo Programa de Aceleração do Crescimento (PAC); pelo Plano de Ação de Ciência, Tecnologia e Inovação, do Ministério da Ciência e Tecnologia; pelo Plano Nacional de Educação, do Ministério da Educação; pelo Programa de Mobilização da Indústria Nacional de Petróleo e Gás Natural; pelo Plano Nacional de Qualificação do Ministério do Trabalho e Emprego; pelo Programa de Educação para a Nova indústria, da CNI, SESI, e SENAI. A PDP cria, além disto, uma estrutura de governança da política, com a coordenação geral da política ficando a cargo do MDIC, além de comitês gestores subordinados aos organismos responsáveis pela condução de seus diferentes programas (MF, MDIC, ABDI, BNDES, MCT).

\section{CONSIDERAÇÕES FINAIS}

Se tomarmos apenas os documentos e as disposições expressas pelos governos dos países indicados acima, revelam-se diversos elementos de convergência. A elevação da capacidade de inovação das empresas, em especial, aparece como objetivo central das políticas industriais de todos eles, associada ao desenvolvimento de ações para domínio das atividades portadoras de futuro. Outro elemento comum é a ênfase conferida às pequenas empresas e ao empreendedorismo tecnológico. A necessidade de articulação entre o Estado e o empresariado, de reorientação do sistema de ciência e tecnologia para a inovação, e de aproxi- 
mação das universidades e institutos de pesquisa com a iniciativa privada, são também aspectos comuns às políticas ou às suas intenções. Neste quadro, alterações nos sistemas de remuneração dos pesquisadores universitários, estímulos ao registro de patentes pelas universidades, apoio a formas diversas de parcerias entre universidades, institutos de pesquisa e empresas aparecem recorrentemente nos documentos de governo, de política industrial e/ou de inovação.

Todavia, se as trajetórias dos países analisados indicam várias dimensões convergentes no que se refere aos objetivos e ao repertório de políticas adotadas, elas se distinguem em relação à importância efetivamente conferida às políticas de inovação e às orientadas para o desenvolvimento das atividades portadoras de futuro, bem como parecem revelar que tais políticas dispõem de eficácia diversa conforme o ambiente institucional, tal como compreendido a partir dos elementos indicados pela abordagem sobre as variedades de capitalismo. Por que, não obstante a inclinação generalizada pela a proximação entre universidades e empresas, os resultados são tão diversos, no que toca à elevação da capacidade inovativa destas últimas? Se o ambiente que emoldura esta relação não estimular as firmas a tomarem a inovação como um diferencial competitivo, não bastam a abertura do sistema nacional de ciência e tecnologia ao mundo empresarial e a simples elevação dos requisitos de capital humano e a infraestrutura de pesquisa e inovação. No limite, a disseminação de padrões de tecnologia industrial básica, medidas de certificação, investimento em capital humano e infraestrutura tecnológica são condições decisivas ao desenvolvimento de esforços inovativos por parte das empresas, mas não são suficientes. A decisão de inovar envolve a percepção de que é possível contornar o custo de oportunidade envolvido em inversões que exigem a mobilização de ativos intangíveis, de retorno incerto. Sem isto, as empresas vão preferir operar nas linhas de menor resistência, acentuando sua competitividade por meio de outros mecanismos.

O papel das políticas públicas é, entre outros, induzir a mudanças de comportamento, seja por alterações no ambiente institucional, seja calibrando as políticas para a obtenção de resultados positivos, no que se refere à elevação da capacidade de inovação das empresas, ainda que não alteradas os elementos centrais do ambiente institucional. Neste sentido, qual poderá ser o caminho do Brasil? Em nossa trajetória tiveram relevo a presença de relações precárias no mercado de trabalho, a reduzida cooperação entre as firmas, o predomínio da produção volta- 
da para dentro, as formas mistas de financiamento - mas com peso expressivo do Estado-, o controle familiar da propriedade-mas com elevada presença estrangeira -, em meio à persistência de formas corporativas de intermediação do Estado com o empresariado. Como, e a que custo, tais características podem se combinar à elevação da capacidade inovativa das empresas brasileiras? O que pode ser reformado ou fortalecido no ambiente institucional? Como elevar a capacidade indutora do Estado e por meio de quais mecanismos e instrumentos de política industrial e de inovação?

Consideradas as características das relações industriais e dos mecanismos de cooperação entre as firmas, o Brasil aproxima-se das formas liberais de capitalismo, o que torna o mecanismo das compras governamentais um elemento central para as políticas públicas voltadas para a inovação. Neste sentido, deve tornar-se parte central da agenda do governo brasileiro a adaptação da legislação a este intento, assegurando que o processo de compras governamentais confira mais importância à qualidade e aos componentes tecnológicos dos produtos do que ao preço. Ademais, deve ser capaz de vir acompanhado de compromissos das empresas com a atividade de inovação. Ao contrário dos EUA, o Brasil não dispõe de um setor de defesa capaz de operar como guarda-chuva para o desenvolvimento de atividades inovadoras, com potencial irradiador sobre todo o tecido industrial. Todavia, o mapeamento das oportunidades no setor energético, no complexo industrial da saúde, na infraestrutura, dentre outros, permite vislumbrar um cenário de enormes possibilidades de utilização das compras governamentais como fator de estímulo à inovação e ao desenvolvimento de atividades portadoras de futuro, vitais a uma mudança de patamar da economia brasileira na estrutura da economia mundial.

Talvez a estrutura industrial brasileira seja muito complexa e diversificada para permitir mecanismos de indução como os desenvolvidos pela Coreia, em que a combinação de controle estatal do sistema bancário e a presença do sistema de contrapartidas favorecem a inclinação das empresas para atividades inovadoras, especialmente para a exportação. Contudo, o peso que tem o BNDES no financiamento da atividade industrial confere ao poder público brasileiro um poder relativamente pouco utilizado. O desafio é acentuar as exigências de contrapartidas em ações inovativas na concessão de financiamento, associadas a medidas que assegurem confiança aos empresários para a realização de tais inversões, no âmbito da segurança de crédito e do segre- 
do industrial. Se a produção para a exportação é tendencialmente mais apta a beneficiar-se deste tipo de política, também a produção para o mercado interno pode dela se valer, dentro da perspectiva de incorporação de amplos contingentes ao mercado de massas nucleado pelas grandes empresas, que, ao lado da elevação da renda, deve envolver a ampliação da capacidade das empresas produzirem mais e mais barato. Adicionalmente, a política de apoio a fusões e aquisições, orientada para a criação de empresas brasileiras capazes de atuar como players internacionais, deveria buscar atingir os setores de atividade tecnologicamente mais dinâmicos, de modo a reduzir o impacto negativo que a elevada internacionalização do mercado interno brasileiro acarreta para as atividades de inovação.

É possível, por outro lado, reforçar os elementos de coordenação que existem no ambiente institucional brasileiro, frequentemente mitigados pela fragmentação dos interesses empresariais e pelo reduzido poder de sanção de que dispõem determinados organismos. A presença da estrutura corporativa de representação de interesses e a experiência de intermediação neocorporativa entre Estado e empresariado, que se reitera de formas diversas ao longo da trajetória brasileira, está longe de desenvolver todas as suas potencialidades para a orquestração de ações cooperativas para atividades de inovação. A ampliação das atribuições das entidades corporativas pode favorecer este intento, tornando-as mais representativas para assegurar a lealdade de seus membros a programas abrangentes. Por seu turno, experiências como as dos fóruns de competitividade podem ser dinamizadas não só para acentuar a cooperação interfirmas, mas, também, como mecanismo de mobilização do setor empresarial pelo Estado, no sentido da produção de bens de conteúdo tecnológico que atendam à demanda do setor público.

Simplicidade é o que não se pode exigir do caso brasileiro. Não só nosso legado institucional é marcado pela presença de diferentes arranjos em certa medida conflitantes, como a diversidade de nossa estrutura produtiva torna difícil a definição de um conjunto reduzido de metas, comuns a todos os setores industriais. Dispomos, contudo, de experiência na utilização de um vasto repertório de instrumentos, desde as medidas de isenção tributária, passando pelo financiamento público e as compras governamentais. A PDP, neste sentido, parece responder a um desafio inescapável que é a construção de políticas seletivas para TODOS os setores industriais, mobilizando este conjunto variado de 
instrumentos. Importa, todavia, estabelecer alguma hierarquia neste processo, de modo a não diluir a importância a ser conferida às ações voltadas ao desenvolvimento de atividades portadoras de mais potencial inovativo. Ademais, é significativo definir procedimentos que permitam a fixação de metas no nível das empresas para o alcance dos objetivos perseguidos pelas políticas setoriais. Por fim, é possível definir uma agenda de reformas institucionais que, considerando as características da governança corporativa das empresas e suas relações com as finanças e o mundo do trabalho, favoreçam a acentuação da colaboração de todos os atores envolvidos na atividade produtiva para processos de inovação.

(Recebido para publicação em junho de 2010) (Versão definitiva em dezembro de 2010)

\section{NOTAS}

1. As fontes de pesquisa para este estudo foram, fundamentalmente, documentos de agências multilaterais e de órgãos dos governos dos países focalizados, muitos deles citados neste artigo. Foram produzidos cinco relatórios, disponíveis na seção Política Industrial Comparada do site da ABDI (http://www.abdi.com.br/Paginas/Default. aspx). O volume 5 do estudo em tela (Variedades de Capitalismo - Formas Institucionais e Inovação Tecnológica), apresenta a relação completa dos documentos pesquisados, com indicação do endereço eletrônico em que podem ser localizados. Os relatórios podem ser encontrados também na seção Projetos do site Laboratório de História Política e Social (LAHPS) da UFJF, no endereço http: / / www.ufjf.br/lahps/.

2. Para um balanço da literatura sobre as variedades de capitalismo, ver Jackson e Deeg (2006).

3. A ausência de mecanismos como a hierarquia e a redes pode ser apontado como um dos limites desta tipologia. Ben Ross Schneider incorpora-os na identificação de outros tipos, que entende presentes na América Latina e na Ásia. Não vamos nos estender sobre este ponto, especialmente porque, como se verá adiante, em nosso entendimento, as virtudes analíticas da noção de variedades de capitalismo estão menos associadas à construção de tipos rigidamente articulados por um único mecanismo de interação estratégica - ou princípio alocativo, como sugere Schneider -, mas às suas possibilidades heurísticas, no sentido da identificação e análise dos domínios de interação estratégica das empresas em diferentes países. Conferir Schneider (2008).

4. Sobre as noções de inovação incremental e inovação radical, ver Freeman e Perez (1988) e, também, Tironi e Cruz (2008) 
5. Uma crítica da correlação indicada por Hall e Soskice, efetuada com base na investigação das patentes registradas pelos EUA e Alemanha, é desenvolvida por Dirk Akkermans, Carolina Castaldi e Bart Los, para os quais as inovações radicais ocorreriam tanto nas economias de mercado liberais, quanto nas economias de mercado coordenadas. Comparando os casos dos EUA e Alemanha, observam que na indústria química e eletrônica, as inovações radicais seriam mais comuns nos primeiros, ao passo que nas indústrias metalúrgica, de máquinas e de transportes seriam mais frequentes na Alemanha. Ver Akkermans, Castaldi e Los (2007). No entanto, importa registrar que os setores assinalados são os indicados por Hall e Soskice como mais representativos dos diferentes tipos de inovação. Ademais, a Alemanha parece concentrar-se em atividades mais distantes daquelas que compõem o núcleo das atividades inovativas dentro do paradigma microeletrônico, no âmbito do qual se processaram as inovações de maior impacto na economia contemporânea. Sobre os paradigmas tecnológicos, ver Freeman e Perez (1988).

6. Diferentes dimensões da ordem institucional e do sistema político são tratados como complementaridades institucionais, que se articulam aos domínios interativos apontados acima, reforçando-os. Assim, modelos políticos mais consociativos seriam tendencialmente afeitos às economias coordenadas, ao passo que nas formas liberais predominariam sistemas em que o poder de agenda e de decisão do Executivo é mais acentuado. Do mesmo modo, sistemas de proteção social amplos e reduzidos conectar-se-iam, respectivamente, às formas coordenadas e liberais (Hall e Soskice, 2001).

7. Vivien Schmidt aponta as dificuldades para inclusão do tema da mudança na teoria das variedades de capitalismo a partir da articulação entre a rational choice, acentuando os interesses dos atores, com o institucionalismo histórico, ressaltando situações de punctuated equilibrium, tal como efetuado por Streeck e Thelen, por força do caráter fixo das preferências para a rational choice e da noção de path dependance para o institucionalismo histórico. Sugere, então, que se dê mais atenção às ideias e aos discursos para análise da mudança no âmbito das variedades de capitalismo (Schmidt, 2006; Streeck e Thelen, 2005; Jackson e Deeg, 2006). Não nos parece que a sugestão de Peter Hall, em texto de 2007, segundo a qual as variedades de capitalismo não podem ser tomadas como um elenco fixo de características institucionais, mas como trajetórias abertas à mudança, altere muito a avaliação que toma a versão original da ideia de variedades de capitalismo como essencialmente impermeável à transformação. Na verdade, o autor assinala como pressões exógenas são absorvidas no âmbito das variedades, levando a mudanças pontuais, sem que a articulação interna de seus elementos efetivamente se modifique (Hall, 2007).

8. Não nos deteremos aqui na análise das relações entre empresariado e Estado nos países em tela, tema do Volume II da pesquisa em que este artigo se assenta. Ver Delgado et alii (2009f).

9. A inserção das economias nacionais no mercado mundial é considerada levando-se em conta sua dimensão, seu grau de abertura, os índices de proteção, além do peso das atividades de maior intensidade tecnológica na produção interna e das manufaturas nas exportações. O grau de abertura leva em conta o peso das exportações e importações no PIB. Os índices de proteção considerados foram os apresentados pelo Banco Mundial (World Bank, 2008), no limite os que estão disponíveis para uma comparação mais abrangente, embora controversos, uma vez que não levam em conta subsídios domésticos e o câmbio. Por fim, consideramos o peso das atividades de 
média e alta tecnologia na produção doméstica e das manufaturas nas exportações para indicar se a economia nacional ocupa um lugar central (peso elevado das atividades de maior intensidade tecnológica e das manufaturas nas exportações), semiperiférica (equilíbrio entre atividades de maior intensidade tecnológica e de entre manufaturas e produtos primários nas exportações) ou periférica (predomínio das atividades de baixa intensidade tecnológica na produção doméstica e dos produtos primários nas exportações). Para mais detalhes, ver Delgado et alii (2009a).

10. O Banco Mundial não apresenta o OTRI da Coreia do Sul, daí sua ausência na Tabela 1. Na nota explicativa de seus índices, assinala, contudo, que a TTRI/MFN é superior à dos países de alto rendimento, as restrições a produtos agrícolas podem alcançar $49 \%$ e que, se preferências são incluídas, podem chegar a $89 \%$, a segunda maior tarifa para produtos agrícolas do mundo. Barreiras não tarifárias são também comuns e podem chegar a 35\%. Conferir World Bank, Republic of Korea: Trade Brief.

11. A presença das maquiladoras, por seu turno, enviesa, no México, os dados relativos à presença de setores de maior intensidade tecnológica na produção industrial e manufaturas na exportação. Importa, ainda, destacar que, embora disponha de um regime tarifário rigoroso, a inclusão no NAFTA implica para o México, a terceira economia mais aberta dentre os países analisados, uma mitigação dos mecanismos de proteção ao seu mercado interno. Por fim, além da dependência em relação ao mercado do NAFTA, o México evidencia uma forte concentração na pauta de exportação. Apenas combustíveis e material de transportes, em 2006, respondiam por $68,57 \%$ das exportações mexicanas. Conferir United Nations, UNCTAD, Unctad Handbook of Statistics, e World Bank, Mexico: Trade Brief.

12. Conforme distinção recolhida em Castro (2002), que aponta a presença de três famílias de política industrial, a saber, as relacionadas à correção de falhas de mercado, as de equiparação e as de inovação; estas últimas são dirigidas especialmente às firmas, ao passo que as segundas teriam como foco os setores. Outra distinção clássica é a que opõe, além das políticas orientadas para a correção de falhas de mercado, as políticas horizontais às políticas verticais, ou seletivas. Enquanto as políticas horizontais seriam dirigidas à criação de condições que, supostamente, beneficiam todos os setores industriais - capital humano, infraestrutura -, as políticas seletivas correspondem a ações dirigidas para favorecer determinados setores ou firmas, para o alcance de resultados que são percebidos pelo Estado como eficientes para a economia em seu conjunto (Chang, 1994:60).

13. Destacamos aqui, como nos demais países focalizados, os programas de governo mais abrangentes, tratados no volume 3 do estudo contratado pela ABDI (Política Industrial: objetivos e instrumentos). Um balanço das políticas setoriais pode ser encontrado no volume 4 deste mesmo estudo (A Política Industrial Brasileira para Setores Selecionados e a Experiência Internacional). 
Ignacio G. Delgado, Eduardo S. Condé, Angelo B. Ésther e Helena da M. Salles

\section{REFERÊNCIAS BIBLIOGRÁFICAS}

ABELSHAUSER, Werner. (2005), The Dynamics of German Industry: Germany's Path toward the New Economy and the American Challenge. New York/Oxford, Berghahn Books.

AKKERMANS, Dirk, CASTALDI, Carolina e LOS, Bart. (2007), “Do ‘Liberal Market Economies' Really Innovate more Radically than 'Coordinated Market Economies'? Hall \& Soskice Reconsidered". Research Memorandum GD-91. Groningen, University of Groningen.

AMABLE, Bruno. (2003), The Diversity of Modern Capitalism. Oxford, Oxford University Press.

ALDRIGHI, Dante Mendes. (2003), "The Mechanisms of Corporate Governance in the United States: An Assessment". Revista Brasileira de Economia, vol. 57, no 3, pp. 469-513.

ARRIGHI, Giovanni. (1997), A Ilusão do Desenvolvimento (2ª ed.). Petrópolis, RJ, Vozes.

BENSUSÁN, Graciela. (2003), “Reformas Laborales en Países Desarrollados y en Desarrollo: Entre el Conservadurismo y la Innovación Institucional". Perfiles Latinoamericanos, no 22, pp. 11-49.

CABRERA, Mercedes e DEL REY, Fernando. (2007), The Power of Entrepreneurs: Politics and Economy in Contemporary Spain. New York, Berghahn Books.

CARVALHO, Nelson Rojas de. (1997), “Do PRI ao Sistema Plural na Transição Mexicana". Lua Nova, nos 40/41, pp. 97-111.

CASTRO, Antonio Barros de. (2002), “A Rica Fauna da Política Industrial e a sua Nova Fronteira". Revista Brasileira de Inovação, vol. 1, no 2, pp.74-253.

CHANG, Ha-Joon. (1994), The Political Economy of Industrial Policy. London, Macmillan Press.

CHO, Dong-Sung e KIM, Jootae. (2007), Outside Directors, Ownership Structure and Firm Profitability in Korea. Disponível em http://www3.interscience.wiley.com/ cgi-bin/fulltext/117967270/PDFSTART. Acessado em maio de 2009.

CHOONG-YONG, A. (2008), Reformas Políticas e Econômicas na Coreia. Tradução de G. Masiero e J. Simonishi. Disponível em http://www.asiayargentina.com/ usp-07.htm. Acessado em 2 de junho de 2009.

CLARK, Paul; DELANEY, John Thomas e FROST, Ann Christine. (2002), Collective Bargaining: In the Private Sector. Chicago, Industrial Relations Research Association.

DELGADO, Ignacio G. (1997), A Estratégia de um Revés - Estado e Associações Empresariais em Minas. Juiz de Fora, Editora da UFJF.

. (2005), “Empresariado e Política Industrial no Governo Lula”, in J. A. Paula (org.), Adeus ao Desenvolvimento: A Opção do Governo Lula. Belo Horizonte, Autêntica.

. (2009), Variedades de Capitalismo e Política Industrial: O Caso Brasileiro em Perspectiva Comparada. Texto completo publicado no XXI Congresso Mundial da IPSA. Santiago. Disponível em http:/ / paperroom.ipsa.org.

; CONDÉ, Eduardo S.; ÉSTHER, Angelo B. e SALLES, Helena S. (2009a), “Modelos Econômicos de Capitalismo: Análise Comparativa dos Ambientes Institucionais de 
Negócios nos EUA, Alemanha, Coreia do Sul, Espanha, Argentina, México e Brasil". Relatório parcial do projeto Estudo Comparativo de Política Industrial: As Trajetórias do Brasil, Argentina, México, Coreia do Sul, EUA, Espanha e Alemanha (vol I). Brasília, ABDI-FUNDEP. Disponível em http://www.abdi.com.br/Paginas/estudo.aspx.

. (2009b), "Política Industrial: Objetivos e Instrumentos". Relatório parcial do projeto Estudo Comparativo de Política Industrial: As Trajetórias do Brasil, Argentina, México, Coreia do Sul, EUA, Espanha e Alemanha (vol. III). Brasília, ABDI-FUNDEP. Disponível em http://www.abdi.com.br/Paginas/estudo.aspx.

. (2009c), “A Política Industrial Brasileira Para Setores Selecionados e a Experiência Internacional". Relatório parcial do projeto Estudo Comparativo de Política Industrial: As Trajetórias do Brasil, Argentina, México, Coreia do Sul, EUA, Espanha e Alemanha (vol. IV). Brasília, ABDI-FUNDEP. Disponível em http: / / www.abdi.com.br / Paginas/estudo.aspx.

. (2009d), “Variedades de Capitalismo e Política Industrial: Formas Institucionais e Inovação tecnológica". Relatório parcial do projeto Estudo Comparativo de Política Industrial: As Trajetórias do Brasil, Argentina, México, Coreia do Sul, EUA, Espanha e Alemanha (vol. V). Brasília, ABDI-FUNDEP. Disponível em http://www.abdi. com.br/Paginas/estudo.aspx.

. (2009e), Estado, Inserção Internacional e Variedades de Capitalismo: Elementos para a Análise dos Capitalismos Reais. Trabalho apresentado no seminário internacional INCT-PPED - Promovendo Respostas à Globalização. Rio de Janeiro, INCT-PPED/IE-UFRJ. Disponível em http://www.ideiad.com.br/seminariointernacional/arquivo6.pdf.

. (2009f), Política Industrial, Estado e Empresariado. Relatório parcial do projeto Estudo Comparativo de Política Industrial: As Trajetórias do Brasil, Argentina, México, Coreia do Sul, EUA, Espanha e Alemanha (vol. II). Brasília: ABDI-FUNDEP. Disponível em http://www.abdi.com.br/Paginas/estudo.aspx.

DHAL, Robert. (1968), Pluralist Democracy in the United States: Conflict and Consent. Chicago, Rand McNally \& Company.

DINIZ, Eli e BOSCHI, Renato. (1979), “Autonomia e Dependência na Representação dos Interesses Industriais". DADOS, no 22, pp. 25-48.

. (1993), “Um Novo Empresariado? Balanço de Tendências Recentes”, in E. Diniz e R. Boschi (eds.), Empresários e Modernização Econômica: Brasil Anos 90. Florianópolis, Editora da UFSC/IDACON.

DINIZ, Simone. (2006), “A Reforma Trabalhista Argentina: A Política de Prêmios e Castigos". Tempo da Ciência, vol. 13, no 25, pp. 157-176.

DUBOFSKY, Melvin e DULLES, Foster. (2004), Labor in America: A History. Chicago, Harlan Davidson.

EBBINGHAUS, Bernhard e VISSER, Jelle. (2000), Trade Unions in Western Europe since 1945. London, Macmillan Press.

EVANS, Peter. (1993), “O Estado como Problema e como Solução”. Lua Nova, nos 28/29, pp. 107-156. 
Ignacio G. Delgado, Eduardo S. Condé, Angelo B. Ésther e Helena da M. Salles

FREEMAN, Christopher e PEREZ, Carlota. (1988), "Structural Crises of Adjustment: Business Cycles and Investment Behavior", in G. Dosi et alii (eds.), Technical Change and Economic Theory. London/New York, Pinter Publishers.

FONTES FILHO, Joaquim Rubens e PICOLIN, Lidice Meireles. (2008), “Governança Corporativa em Empresas Estatais". Revista de Administração Pública, vol. 42, no 6, PP. 1163-1188.

GEROLOMANO, Mateus Cecílio et alii. (2008), “Clusters e Redes de Cooperação de Pequenas e Médias Empresas: Observatório Europeu, Caso Alemão e Contribuições ao Caso Brasileiro". Revista Gestão \& Produção, vol. 15, no 2, pp. 351-365.

GOUREVITCH, Peter. (1986), Politics in Hard Times. Ithaca, Cornell University Press.

e SHINN, James. (2005), Political Power \& Corporate Control: The New Global Politics of Corporate Governance. Princeton/Oxford, Princeton University Press.

GRAHAM, Edward M. (2003), Reforming Korea's, Industrial Conglomerates. Washington, Institute for Internacional Economics.

GUIMARÃES, Alexandre Queiroz. (2006), “O Capitalismo Coordenado Alemão: Do Boom do Pós-Guerra à Agenda 2010". Lua Nova, no 66, pp. 23-56. Disponível em: http:/ / www.scielo.br/pdf/ln/n66/29083.pdf. Acessadoo em 23 de abril de 2009.

. (2007a), “Modelos de Capitalismo e Economia Política Comparada: Instituições, Performance e as Respostas Alemã e Japonesa aos Desafios Recentes". DADOS, vol. 50, no 1, pp. 159-188. Disponível em: http://www.scielo.br/pdf/dados/v50n1/ a06v50n1.pdf. Acessado em 23 de abril de 2009.

. (2007b), “Estado e Economia na Coreia do Sul - do Estado Desenvolvimentista à Crise Asiática e a Recuperação Posterior". Disponível em: http://www.sep.org. br/artigo/741_28c2f23ba90d0a2f88ea42a4edb640a5.pdf? PHPSESSID=93c69bf512 f15aacfd4cac3a9c . Acessado em 27 de julho de 2009.

HAGGARD, Stephan; LIM, Wonhyuk. e KIM, Euysung. (2003), Economic Crisis and Corporate Restructuring in Korea: Reforming the Chaebol. Cambridge, Cambridge University Press.

HALL, Peter. (2007), "The Evolution of Capitalism in Europe". Trabalho apresentado no Encontro Anual da American Political Science Association. Chicago, Illinois, 1 de setembro.

e SOSKICE, David. (2001), Varieties of Capitalism. Oxford, Oxford University Press.

HANCKÉ, Bob; RHODES, Martin e THATCHER, Mark. (2007), “Introduction: Beyond Varieties of Capitalism", in Beyond Varieties of Capitalism: Conflict, Contradictions, and Complementarities in the European Economy. Oxford, Oxford University Press.

HOLLINGSWORTH, J. Rogers e BOYER, Robert. (1997), Contemporary Capitalism: The Embeddedness of Institutions. Cambridge, Cambridge University Press.

ITIRO, Andrea. (2003), Flexibilização dos Mercados de Trabalho: Um Panorama do Debate Internacional". Pesquisa \& Debate, vol. 14, no 1, pp. 60-70.

JACKSON, Gregory e DEEG, Richard. (2006), “How Many Varieties of Capitalism”. Discussion Paper 06/2. Colônia, Max Planck - Institut für Gesellschaftsforschung Köln. Disponível em http:/ / www.mpifg.de.

\section{4}


JENKINS-SMITH, Hank e SABATIER, Paul. (1993), "The Advocacy Coalition Framework: Assessment, Revisions and Implications for Scholars and Practioners", in H. Jenkins-Smith e P. Sabatier (eds.), Policy Change and Learning: An Advocacy Coalitions Approach. Boulder, Westwiew.

KANTIS, Hugo et alii. (2005), "Clusters y Nuevos Polos Emprendedores Intensivos en Conocimiento en Argentina". Disponível em http://www.insme.org/documenti/ArgentinaClusters.pdf. Acessado em 13 de abril de 2009.

KIM, Linsu. (2005), Da Imitação à Inovação: A Dinâmica do Aprendizado Tecnológico da Coreia. Campinas, Editora da Unicamp.

KUCKULENTZ, Anja. (2007), Studies on Continuing Vocational Training in Germany: An Empirical Assessment. Mannheim, Zew Economic Studies.

LEAL, Maria José e CAMURI, Walter César. (2008), “A Governança Corporativa e os Modelos Mundialmente Praticados". Revista de Ciências Gerenciais, vol. XII, no 15, pp. 59-74.

LEHMBRUCH, Gerhard e SCHMITTER, Philippe. (1982), Patterns of Corporatist Policy-Making. London, Sage.

LEOPOLDI, Maria Antonieta. (2000), Política e Interesses. São Paulo, Paz e Terra.

LOBO, Valéria M. (2010). Fronteiras da Cidadania: Sindicatos e (des)Mercantilização do Trabalho no Brasil (1950-2000). Belo Horizonte, Argumentvm.

MANCUSO, Wagner Pralon. (2004), “O Lobby da Indústria no Congresso Nacional: Empresariado e Política no Brasil Contemporâneo". DADOS, vol. 47, no 3, pp. 505-547.

MEDINA, Ignacio N. (2003), El Sindicalismo Mexicano en la Transición al Siglo XXI. Buenos Aires/Montevidéu, Libros en Red.

NOVAES, Ana. (2004), “Mercado de Capitais: Lições da Experiência Internacional”. Disponível em: http://iepecdg.com/DISK\%201/Arquivos/Papers/LicoesdaExperienciaInternacional-AnaNovaes.pdf. Acessado em 30 de março de 2009.

OFFE, Claus e RONGE, Volker. (1984), “Teses sobre a Fundamentação do Conceito de Estado Capitalista e sobre a Pesquisa Política de Orientação Materialista", in C. Offe (org.), Problemas Estruturais do Estado Capitalista. Rio de Janeiro, Tempo Brasileiro, pp. 122-137.

PALOMINO, Héctor e TRAJTEMBERG, David. (2006), “Una Nueva Dinámica de las Relaciones Laborales y la Negociación Colectiva en la Argentina". Revista de Trabajo, Ano 2, no 3.

POLANYI, Karl. (1980), A Grande Transformação. Rio de Janeiro, Campus.

PUGA, Fernando Pimentel. (2002), O Apoio Financeiro às Micro, Pequenas e Médias Empresas na Espanha, no Japão e no México. Disponível em http://www.bndespar.com. br/conhecimento/td/Td-96.pdf. Acessado em 30 de março de 2009.

RABELO, Flávio e SILVEIRA, José Maria da. (1999), “Estruturas de Governança e Governança Corporativa: Avançando na Direção da Integração entre as Dimensões Competitivas e Financeiras". Texto para Discussão, no 77, IE/Unicamp. 
RAMOS, Sérgio Motejunas. (2008), A Economia Política e os Contratos Coletivos de Trabalho nos EUA, México e Brasil: Aspectos Comparativos. Tese em História, Faculdade de Filosofia, Letras e Ciências Humanas, Universidade de São Paulo, São Paulo. Disponível em http://www.teses.usp.br/teses/disponiveis/8/8137/tde11092008-161454/. Acessado em 2 de junho de 2009.

ROCHA, Júlio Cesar de S. da. (2007), “Direito do Trabalho nos Estados Unidos: Considerações sobre as Bases do Sistema Norte-Americano". Revista Jurídica. Disponível em http:/ / www.facs.br/revistajuridica / edicao_janeiro2007/convidados/con3.doc. Acessado em maio de 2009.

SANTOS, Luiz Alberto. (2008), “Regulamentação das Atividades de Lobby e seu Impacto sobre as Relações entre Políticos, Burocratas e Grupos de Interesse no Ciclo de Políticas Públicas: Análise Comparativa dos Estados Unidos e Brasil". Disponível em http://bdtd.bce.unb.br/tedesimplificado/tde_busca/arquivo.php?codArquivo $=4798$. Acessado em 28 de setembro de 2009 .

ROZICKI, Cristiane. (1997), “A Reforma Sindical e Trabalhista. ALCA, MERCOSUL e Espanha. A Pluralidade Sócio-Econômica Reconhecida: Autenticidade Representativa e Eficiência na Contratação Coletiva". Revista Seqüência, Ano 18, no 34, pp. 67-82. Disponível em http://www.buscalegis.ufsc.br/revistas/index.php/buscalegis/ article/view/22605/22168. Acessado em 2 de junho de 2009.

SCHMIDT, Vivien. (2006), Bringing the State Back into the Varieties of Capitalism and Discourse into the Explanation of Change. Trabalho apresentado no Encontro Anual da American Political Science Association (APSA). Filadélfia, 31 de agosto-3 de setembro.

SCHMITTER, Philippe e STREECK, Wolfgang. (1999), "The Organization of Business Interests: Studying the Associative Action of Business in Advanced Industrial Societies". MPIfG Discussion Paper, no 99/1. Germany, Max-Planck-Institut für Gesellschaftsforschung. Disponível em http:/ / www.mpi-fg-koeln-mpg.de. Acessado em 10 de setembro de 2009.

SCHNEIDER, Ben Ross. (2004), Business Politics and the State in Twentieth-Century Latin America. Cambridge, Cambridge University Press.

. (2008), Comparing Capitalisms: Liberal, Coordinated, Network and Hierarchical Varieties (mimeo).

SROUR, Gabriel. (2005), “Práticas Diferenciadas de Governança Corporativa: Um Estudo sobre a Conduta e a Performance das Firmas Brasileiras". Revista Brasileira de Economia, vol. 59, no 4, pp. 635-674. Disponível em http://www.scielo.br/pdf/ rbe/v59n4/a06v59n4.pdf. Acessado em 3 de maio de 2009.

STREECK, Wolfgang e THELEN, Kathleen. (2005), "Introduction", in W. Streeck e K. Thelen (eds.), Beyond Continuity: Institutional Change in Advanced Political Economies. Oxford, Oxford University Press.

SUZIGAN, Wilson e FURTADO, João. (2005), "Política Industrial e Desenvolvimento", in J. A. de Paula (org.), Adeus ao Desenvolvimento: A Opção do Governo Lula. Belo Horizonte, Autêntica. 
Cenários da Diversidade: Variedades de Capitalismo e Política Industrial...

TIRONI, Luís F. e CRUZ, Bruno de O. (2008), “Inovação Incremental ou Radical: Há Motivos para Diferenciar? Uma Abordagem com Dados da PINTEC". Texto para Discussão nํ1360. Brasília, IPEA.

VERMA, Anil; KOCHAN, Thomas e LANSBURY, Russell. (1995), Employment Relations in the Growing Asian Economies. New York, Routledge.

WERNECK VIANNA, Luiz. (1976), Liberalismo e Sindicato no Brasil. Rio de Janeiro, Paz e Terra.

WHITLEY, Richard. (1999), Divergent Capitalisms: The Social Structuring and Change of Business Systems. Oxford, Oxford University Press. 
Ignacio G. Delgado, Eduardo S. Condé, Angelo B. Ésther e Helena da M. Salles

\begin{abstract}
Scenarios of Diversity: Varieties of Capitalism and Industrial Policy in the United States, Germany, Spain, Korea, Argentina, Mexico, and Brazil (1998-2008)

This article analyzes how different institutional domains related to varieties of capitalism appear in the literature (corporate governance, relations between companies, industrial relations, employer-employee relations, and qualification processes) in the United States, Germany, Spain, Korea, Argentina, Mexico, and Brazil, and adds dimensions like the relationship between the business community and the state and patterns of insertion in the national economies and the world market, in order to identify the different institutional configurations in which enterprises operate in these countries. The article then describes the main characteristics of the industrial policies developed by the various countries, considering their relevance for both these configurations and the Brazilian context, in order to identify the institutional policies and changes that could help Brazil achieve greater success in increasing the companies' capacity for technological innovation.
\end{abstract}

Key words: varieties of capitalism; ind ustrial policy; technological innovation

\title{
RÉSUMÉ
}

Scènes de la Diversité: Variétés de Capitalisme et Politique Industrielle aux USA, en Allemagne, Espagne, Corée, Argentine, au Mexique et Brésil (1998-2008)

Dans cet article, on examine comment apparaissent aux EUA, en Allemagne, Espagne, Corée, Argentine, au Mexique et Brésil les différents domaines institutionnels analysés par la littérature concernant les variétés de capitalisme (gouvernance entrepreneuriale, rapport entre les entreprises, relations industrielles, relations entreprises-employés, processus de qualification), en y incorporant des aspects comme les rapports Etat patronat ainsi que les modèles d'insertion des économies nationales dans le marché mondial, de façon à reconnaitre les différents cadres institutionnels dans lesquels opèrent les entreprises de ces pays. Ensuite, on présente les principales caractéristiques des politiques industrielles menées par les pays mentionnés, compte-tenu de leur bien-fondé vis-à-vis de ces éléments et du contexte brésilien, de façon à définir les politiques et les changements institutionnels ayant le plus de chance de succès au Brésil quant à l'augmentation de la capacité d'innovation technologique de ses entreprises.

Mots-clés: variétés de capitalisme, politique industrielle; innovation technologique 